\title{
ROCK FRACTURES NEAR FAULTS: SPECIFIC FEATURES OF STRUCTURAL-PARAGENETIC ANALYSIS
}

\author{
Yu. P. Burzunova \\ Institute of the Earth's Crust, Siberian Branch of RAS, Irkutsk, Russia
}

\begin{abstract}
The new approach to structural-paragenetic analysis of near-fault fractures [Seminsky, 2014, 2015] and specific features of its application are discussed. This approach was tested in studies of fracturing in West Pribaikalie and Central Mongolia. We give some recommendations concerning collection, selection and initial processing of the data on fractures and faults. The analysis technique is briefly described, and its distinctive details are specified. Under the new approach, we compare systems of natural fractures with the standard joint sets. By analysing the mass measurements of the orientations of joint sets in a fault zone, it becomes possible to reveal the characteristics of this fault zone, such as its structure, morphogenetic type, etc. The comparative analysis is based on the identification of the main fracture paragenesis near the faults. This paragenesis is represented by a triplet of mutually perpendicular joint sets. The technique uses the qualitative approach to establish the rank hierarchy of fractures and stress fields on the basis of genetic subordination. We collect and analyse the data on tectonic fractures identified from a number of indicators, the main of which are the geometric structure of the (systematic or chaotic) fracture system, and shear type of fractures. The new technique can be applied to analyse other genetic types of fractures (primary, hypergenic), provided that tectonic stresses were significantly involved in fracturing, which is evidenced by the corresponding indicators. Methods for conducting geological and structural observations are uniform for all sites and points, and increasing the number of observation points provides for a more effective use of the new technique. In our paper, we give specific parameters for constructing circle fracture diagrams. All the maximums in the diagram are involved in the analysis for comparison with the standard patterns. Errors caused by random coincidence are minimized by using special criteria to estimate the diagrams, and the reliability of the solutions is thus ensured. This paper considers various problems related to interpretations of natural fracture systems, concerning the angles between the conjugate joint sets, the presence of non-standard fracture parageneses, fault zones of mixed types, and structural-material inhomogeneities. The recommendations based on our experience of selection and processing of input field data can be viewed as a supplement to the method of analysis used for specialized mapping of faults zones and detection of stress fields [Seminsky, 2014, 2015]. The discussed information can be useful for those who are willing to successfully use this new approach to investigate the fault systems in the upper crust and solve applied and fundamental problems in the studies of faulting.
\end{abstract}

Key words: joint; joint system; fault zone; fracture paragenesis; tectonic jointing; conjugate fractures; triplet of joint sets; stress field

\section{RESEARCH ARTICLE}

Received: January 31, 2017

Recommended by K.Zh. Seminsky

Revised: March 15, 2017

Accepted: March 23, 2017

For citation: Burzunova Yu.P., 2017. Rock fractures near faults: specific features of structural-paragenetic analysis. Geodynamics \& Tectonophysics 8 (3), 673-693. doi:10.5800/GT-2017-8-3-0312.

Для цитирования: Бурзунова Ю.П. Трещины горных пород вблизи разломов: особенности применения структурно-парагенетического анализа // Геодинамика и тектонофизика. 2017. Т. 8. № 3. С. 673-693. doi:10.5800/GT-2017-8-3-0312. 


\title{
ТРЕЩИНЫ ГОРНЫХ ПОРОД ВБЛИЗИ РАЗЛОМОВ: ОСОБЕННОСТИ ПРИМЕНЕНИЯ СТРУКТУРНО-ПАРАГЕНЕТИЧЕСКОГО АНАЛИЗА
}

\author{
Ю. П. Бурзунова \\ Институт земной коры СО РАН, Иркутск, Россия
}

\begin{abstract}
Аннотация: Рассмотрены особенности практического применения нового подхода к структурно-парагенетическому анализу приразломных трещин [Seminsky, 2014, 2015], полученные в процессе опробования методики для изучения трещиноватости в Западном Прибайкалье и Центральной Монголии. В этой связи даны рекомендации по сбору и первоначальной обработке фактического материала. Приведено краткое описание метода и его отличительные детали. Новый подход заключается в сравнении природных сетей трещин с эталонными трещинными сетями. Он позволяет определить характеристики разломной зоны (строение, морфогенетический тип и др.) на основе массовых замеров ориентировок трещиноватости. Сравнительный анализ базируется на выявлении основного разрывного парагенезиса вблизи разломов - это тройка взаимно перпендикулярных систем трещин. В методике используется качественный подход к ранговой иерархии разрывов и полей напряжений, основанный на генетической соподчиненности. Фактическим материалом служит трещиноватость тектонического происхождения, для идентификации которой приведен ряд признаков основными являются геометрическая структура трещинной сети (системная или хаотическая) и сколовый тип трещин. Другие генетические типы трещин (первичные, гипергенные) можно анализировать новым методом при условии существенного участия в их формировании тектонических напряжений, что определяется наличием соответствующих признаков. Приемы проведения геолого-структурных наблюдений едины для всех пунктов, увеличение числа которых повышает эффективность метода. Приведены конкретные параметры для построения круговых диаграмм трещиноватости. К анализу привлекаются все максимумы на диаграмме для сравнения с эталонными трафаретами. Специальные критерии оценки диаграмм минимизируют ошибки случайного совпадения и обеспечивают надежность полученных решений. Рассмотрены различные вопросы интерпретации природных трещинных сетей, касающиеся угловых величин между сопряженными системами трещин, наличия нетипичных трещинных парагенезисов и разломных зон смешанного типа, структурно-вещественных неоднородностей. Представленные в статье рекомендации по применению нового структурно-парагенетического метода на основании полученного опыта в отношении подбора исходных полевых данных и их обработки служат практическим дополнением к методике проведения анализа в процессе спецкартирования разломных зон и выявления полей напряжений [Seminsky, 2014, 2015]. Предложенные сведения будут полезны для успешного освоения нового подхода по исследованию разломной структуры верхней части земной коры при решении прикладных и фундаментальных задач, связанных с изучением разломов.
\end{abstract}

Ключевые слова: трещины; трещинная сеть; разломная зона; парагенезис разрывов; тектоническая трещиноватость; сопряженные разрывы; тройка систем трещин; поле напряжений

\section{1. ВВЕДЕНИЕ}

Трещины в горных породах, связанные с формированием крупных тектонических разрывов, являются важным объектом для исследований, направленных на решение прикладных задач инженерной геологии, сейсмологии, рудной геологии, а также в фундаментальном аспекте - для геодинамических реконструкций. Формирование разлома, как правило, предваряется и сопровождается образованием более мелких разломов и трещин. Они развиваются в едином поле тектонических напряжений и образуют структурный парагенезис разрывов в пределах области динамического влияния разлома [Sherman et al., 1983]. На земной поверхности для изучения доступен плоский срез этой области разломная зона.
Новый подход к анализу приразломной трещиноватости [Seminsky, Burzunova, 2007; Seminsky, 2014, 2015] позволяет получить характеристики разломной зоны (строение, ориентировка, парагенезис вторичных разрывов, морфогенетический тип, поле напряжений), используя массовые данные об элементах залегания трещин. Он успешно дополняет традиционные способы исследования разломов земной коры. Данный метод является основой для спецкартирования разломных зон и полей напряжений с целью расшифровки разломноблоковой структуры природных регионов.

В настоящей статье подробно рассмотрены особенности практического применения нового подхода. Они выявлены нами в ходе опробования метода на природных объектах (рис. 1) в районах Западного Прибайкалья (Приольхонье, зоны разло- 
мов Обручевской системы) и Центральной Монголии (место локализации разломов Могод, Тулэт, Хустай, Эмээлт), расположенных в пределах Центрально-Азиатского складчатого пояса и частично на Сибирской платформе. Изучена трещиноватость в метаморфических породах, интрузивных массивах, эффузивных толщах, осадочных отложениях разного возраста (рис. 1, Б). Массовые измерения ориентировок трещин (более 36 тыс. шт.) проведены в 417 пунктах наблюдения, построены круговые диаграммы трещиноватости (рис. $1, B$ ). На шести детальных участках метод применен в профильном или площадном варианте. Результаты проведенного анализа частично опубликованы [Burzunova, 2009, 2013, 2015; Seminskii et al., 2012].

Опробование методики показало, что на практике возникает множество вопросов, касающихся как самого процесса анализа трещинной сети, так и правильного подбора исходных данных, а также обоснованности применения метода для трещин разного генезиса, развитых в различных тектонических и геолого-структурных условиях. Подобные трудности появляются на наиболее важных этапах спецкартирования - подготовки и обработки, включающих сбор фактического материала и первичную интерпретацию трещинных парагенезисов. Эти вопросы подробно рассмотрены в статье. Кроме того, полученные данные позволили выделить дополнительные рекомендации для эффективного использования нового метода и достижения качественных результатов.

\section{2. ТЕОРЕТИЧЕСКИЕ ОСНОВЫ И МЕТОДИКА АНАЛИЗА ТРЕЩИННЫХ СЕТЕЙ}

Представления о структурных парагенезах и парагенетические методы анализа разрывных нарушений (структурно-парагенетические методы) развивались в работах М.В. Гзовского, А.В. Лукьянова, П.Н. Николаева, В.Н. Даниловича, С.И. Шермана, Л.М. Расцветаева, М.Л. Коппа, М.А. Гончарова, О.Б. Гинтова, Л.А.Сим, К.Ж. Семинского и других исследователей. При общих принципах изучения парагенезисов геологических структур и механизмов их формирования методы отличают следующие детали: масштабный уровень и разновидность изучаемых структур (трещины, разломы, линеаменты), тип тектонических деформаций (разрывные, складчатые), способ получения исходного фактического материала (статистические измерения, моделирование, картирование структур по натурным наблюдениям, дешифрирование аэро- и космоснимков, выделение линеаментов рельефа на топографических картах), тип второстепенных разрывов (оперяющие, опережающие), используемый структурный парагенезис (пара сопряженных сколов, пояса и другие структурные рисунки), условия применимости методики и т.д.

Главное отличие рассматриваемого ниже методического подхода состоит в виде используемого парагенезиса, это тройка перпендикулярных систем приразломных трещин [Seminsky, 2003; Seminsky, Gladkov, 1991]. Новый подход развивает методы М.В. Гзовского (реконструкция осей напряжений [Gzovsky, 1975]), П.Н. Николаева (статистический способ изучения «немой» трещиноватости [Nikolaev, 1992]) и не противоречит другим парагенетическим методам. Теоретические принципы нового анализа трещин подробно изложены в цитированных выше работах и состоят в следующем.

Доминирующим элементом разрывных сетей в разломных зонах является тройка взаимно ортогональных систем трещин - простой структурный парагенезис тектонического происхождения. Две системы - главная и второстепенная - являются классической парой сопряженных систем трещин скалывания (сколы Риделя) (рис. 2, A). При низких давлениях в приповерхностных условиях величина угла между ними при оси сжатия существенно зависит от типа пород [Gzovsky, 1975], в нормальных условиях она находится в основном в пределах $30-70^{\circ}$.

Третья дополнительная система трещин отрыва образуется на бо́льших глубинах и ориентирована перпендикулярно главной и второстепенной системам (рис. 2,5 ), что обеспечивает их взаимную приблизительную ортогональность в тройке. Дополнительная система возникает при переиндексации осей главных нормальных напряжений перпендикулярно «новой» оси наименьшего сжатия $\left(\sigma_{\text {раст }}\right.$ на рис. 2,5$)$. Это становится возможным в условиях хрупкого транспрессивного (в обстановке трехосного сжатия) скалывания при осесимметрическом напряженном состоянии [Seminsky, 2003].

Вместе с тем глубинные условия влияют на величину угла между сопряженными сколами в тройке, который в среднем равен $80^{\circ}$ (рис. 2, Б). Определяющую роль играет, во-первых, всестороннее давление, возрастание которого ведет к увеличению угла скалывания (до 45) [Gzovsky, 1963]. Вовторых, на угол скалывания влияют девиаторные напряжения, определяющие тип динамической обстановки в массиве - сжатие, растяжение или сдвиг [Seminskii, 1997; Burzunova, 2011]. В-третьих, первоначальный угол между сопряженными трещинами, равный двойному углу скалывания, может быть «пассивно» увеличен при развороте трещин в процессе последующей пластической деформации [Nikolaev, 1992] до $90^{\circ}$ и более.

Количественные закономерности комплексного воздействия этих факторов установить непросто. В 

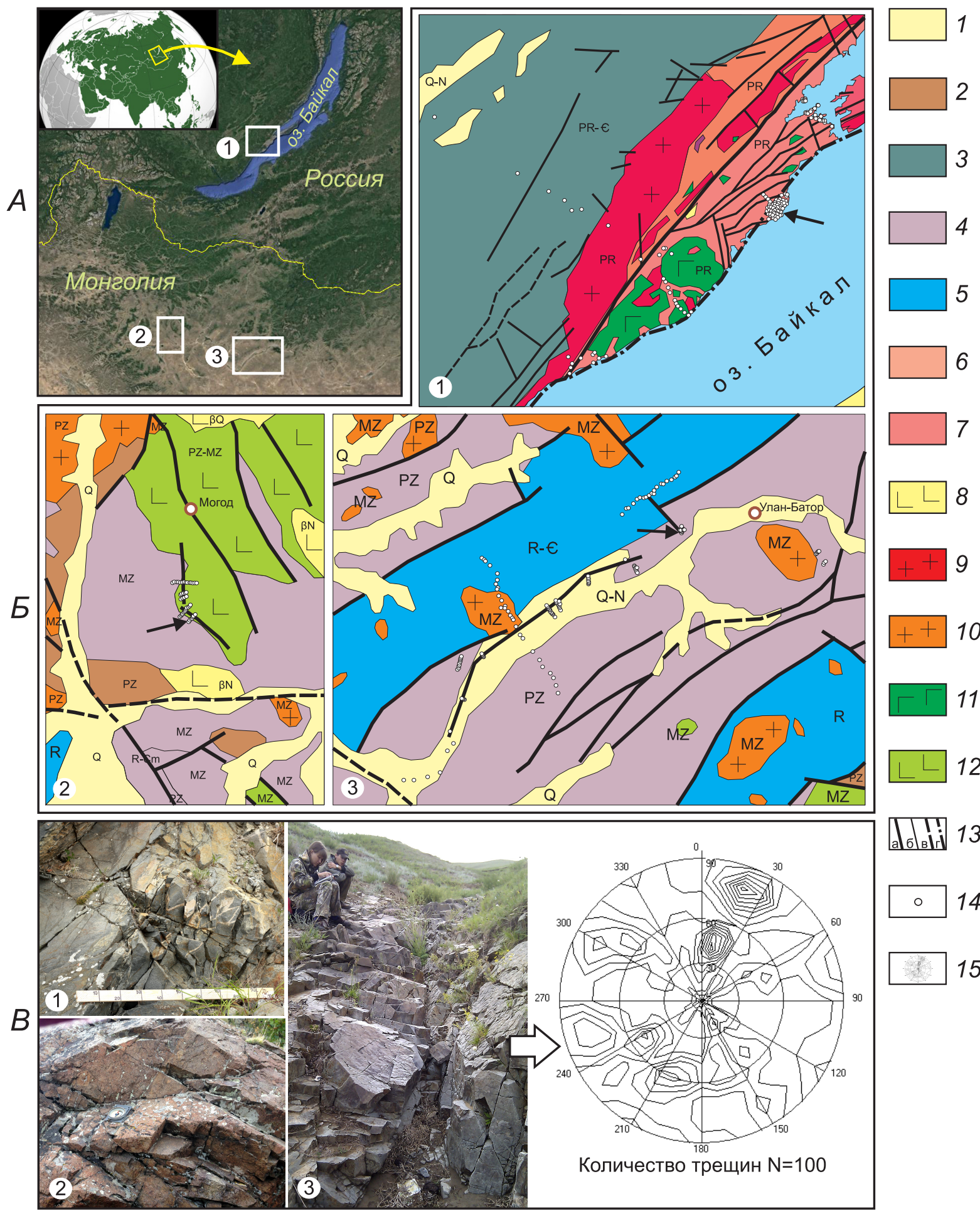

Количество трещин $\mathrm{N}=100$

Рис. 1. Районы исследования приразломной трещиноватости: Приольхонье (1), Могод (2), Хустай (3).

$A$ - местоположение на космоснимке; Б - геологическое строение (по [Dodin, 1986; Yanshin, 1989] с упрощениями) и положение пунктов наблюдения; $B$ - примеры трещинных сетей на детальных участках (их положение отмечено стрелками на рис. 1,5 ) и круговая диаграмма трещиноватости, представленной на рис. $1, B-3.1$ - аллювиально-озерные отложения; 2 - песчаники, алевролиты; 3 - песчаники, алевролиты, доломиты, глинистые и углистые сланцы, мергели; 4 - породы молассовой угленосной, терригенной (включая граувакковую, флишоидную, туфогенную), яшмово-кремнисто-терригенной формаций; 5 - кремнистые, зеленые, черные сланцы; 6 - кварциты двуслюдяные и высокоглиноземистые, гранатово-слюдяные и другие кристаллические сланцы, амфиболиты; 7 - биотитовые и роговообманковые гнейсы, кристаллические сланцы, мраморы, кварциты; 8 - базальтоиды; 9 - граниты лейкократовые биотитовые порфировидные; 10 - граниты, гранодиориты, тоналиты, плагиограниты; 11 диориты, габбро-диориты; 12 - базальты, трахибазальты, андезиты, трахиандезиты, андезит-риолит-трахириолиты; 13 - разломы достоверные крупные (а) и более мелкие (б), предполагаемые (в), скрытые под кайнозойскими отложениями (г); 14 пункты наблюдения за трещинами; 15 - круговая диаграмма трещиноватости в изолиниях относительной плотности полюсов трещин: стереографическая проекция Вульфа, верхняя полусфера, величина окна осреднения - $10^{\circ}$, шаг между уровнями изолиний - 1 \% (на рис. 3 и далее диаграммы с теми же параметрами, без градусной сетки, с указанием направления на север). 
Fig. 1. Studied areas of fracturing near faults: Olkhon (1), Mogod (2) and Hustai (3).

$A$ - location in the satellite image; $E$ - geologic structure according to [Dodin, 1986; Yanshin, 1989] (simplified), and locations of observation points; $B$ - examples of fracture systems on sites studied in detail (the locations are marked by arrows in Fig. 1, 5 ), and circle fracture diagram (see Fig. 1, B-3). 1 - alluvial-lacustrine deposits; 2 - sandstone, siltstone; 3 - sandstone, siltstone, dolomite, clay and carbonaceous shales, marls; 4 - rocks of molasse coal-bearing, terrigenous (including graywacke, flyschoid, tuffaceous), jasperlode-siliceousclastic formations; 5 - siliceous, green, and black shales; 6 - binary-mica quartzites and high-alumina, garnet-mica and other crystalline schists, amphibolites; 7 - biotite and hornblende gneisses, schists, marbles, quartzites; 8 - bazaltoids; 9 - leucocratic biotite porphyric granites; 10 - granites, granodiorites, tonalities, plagiogranites; 11 - diorites, gabbro-diorites; 12 - basalts, trachybasalts, andesites, trachyandesites, andesite-rhyolite-trachyrhyolites; 13 - confirmed large (a) and smaller (б) faults, assumed faults (в), faults under Cenozoic deposits (г); 14 - fracture observation points; 15 - circle fracture diagram in isolines of relative density of fracture poles: stereographic Wolf projection, upper hemisphere, averaging window value $-10^{\circ}$, distance between the levels of isolines $-1 \%$ (in Fig. 3 and below, the diagrams have similar parameters; the grade grid is not shown; the direction to the north is shown).

горных породах разного типа наблюдаются равные по величине углы, а в однотипных породах разных регионов - существенно различающиеся углы. Тем не менее в разломных зонах наиболее отчетливо проявлена зависимость результирующего угла от динамической обстановки (что не исключает при этом остальные факторы). Средняя величина угла между сопряженными разрывами в приразломной трещиноватости (Прибайкалье, Средняя Азия, Индокитай) возрастает в ряду: обстановка растяжения - сдвига - сжатия и равна соответственно $75^{\circ}-81^{\circ}-91^{\circ}$ [Burzunova, 2011]. При этом статистический размах вариаций углов составляет $16^{\circ}-35^{\circ}-50^{\circ}$ (вариации обусловлены, в том числе, и другими факторами), а минимальные значения углов в выборке у всех типов примерно одинаковы - около $70^{\circ}$.

Тройственный парагенезис (рис. 2, Б) наиболее часто встречается в зоне тектонического разлома. Простые трещинные сети в виде одной тройки систем трещин (рис. $3, A$ ) наблюдаются, как правило, в мелких разломных зонах, а также в периферийных частях и отдельных фрагментах крупных разломных зон [Sherman et al., 1992]. Такие сети относятся к системным (systematic) [Chernyshev, 1983; Twiss, 1992; Pluijm, 2004], их количество в
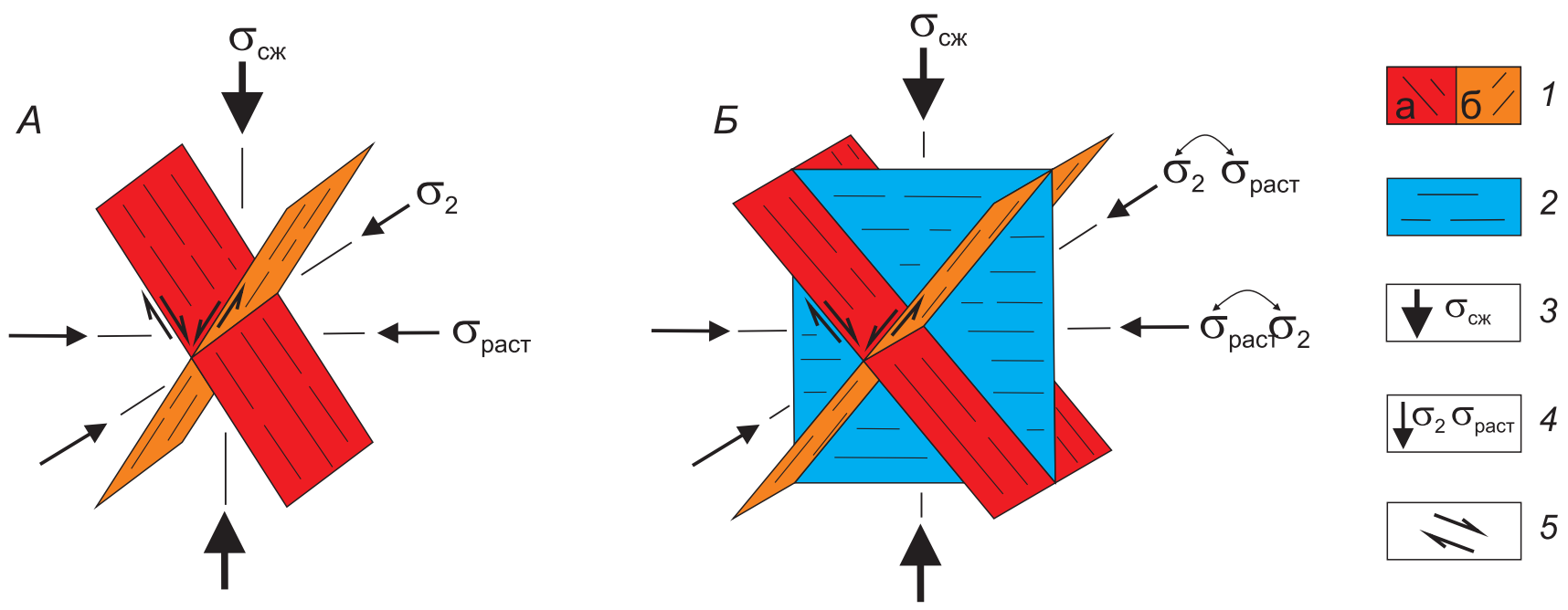

Рис. 2. Простые парагенезисы тектонических трещин в локальном объеме горных пород.

$A$ - пара сопряженных систем сколов в близповерхностных условиях; $E$ - тройка систем трещин при осесимметрическом сжатии (по [Seminsky, 2014]). 1 - главная (а) и второстепенная (б) системы трещин скалывания; 2 - дополнительная система трещин отрыва; 3 - направление действия существенно преобладающего по величине главного нормального сжимающего напряжения;

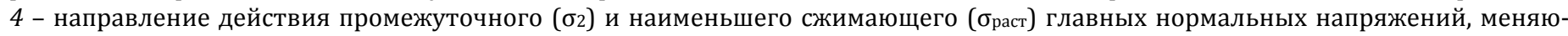
щихся местами при переиндексации (Б) (дугообразная стрелка); 5 - направления скольжения.

Fig. 2. Simple parageneses of tectonic fractures in the local volume of rocks.

$A$ - couple of conjugated joint sets in the near-surface conditions; $\overline{-}$ - triplet of joint sets (axially symmetric compression), after [Seminsky, 2014]. 1 - main (a) and secondary (б) shear joint sets; 2 - supplementary extension joint set; 3 - direction of the considerably stronger main normal compressive stress; 4 - direction of transitional $\left(\sigma_{2}\right)$ and smallest main normal compressive $\left(\sigma_{\text {pacr }}\right)$ stresses that replace each other in case of re-indexation (b) (curved arrow); 5 - direction of sliding. 


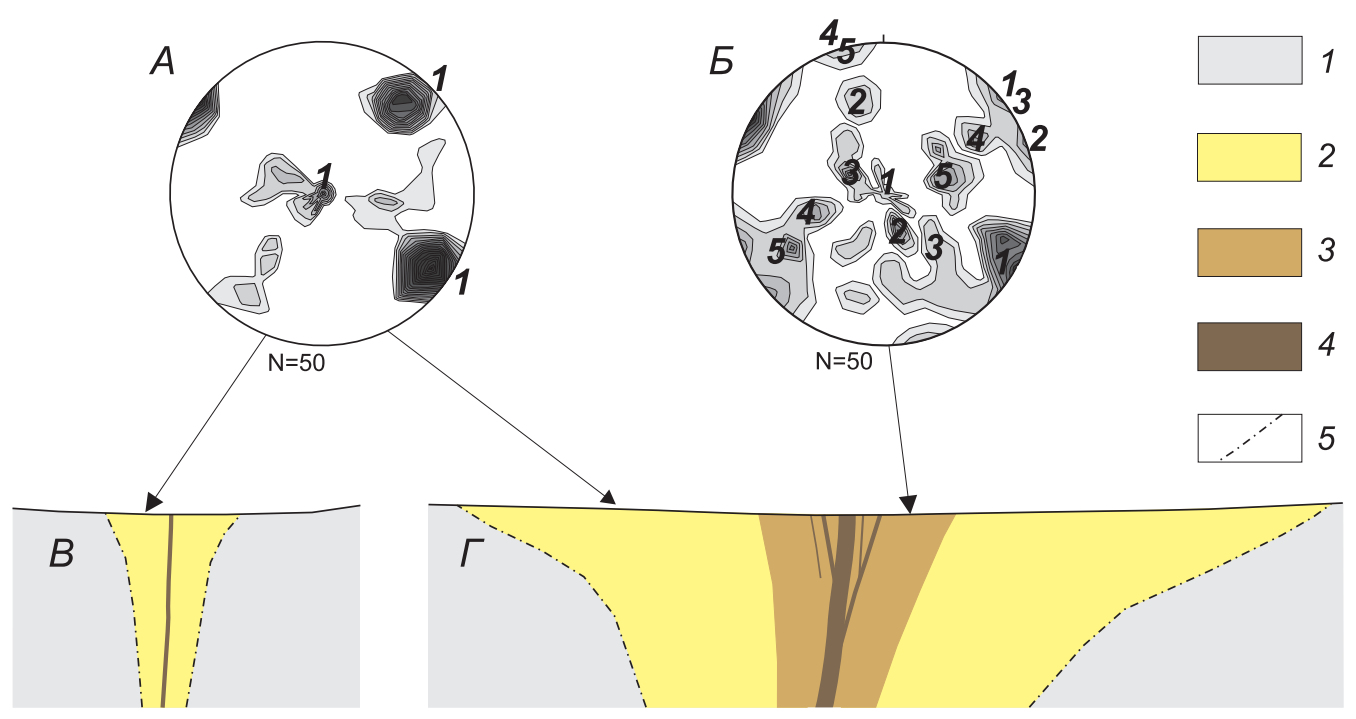

Рис. 3. Трещинные сети в зоне мелкого и крупного разлома.

$A, E$ - системная $(A)$ и хаотическая $(5)$ сети (в виде круговых диаграмм, одинаковыми цифрами показаны тройки систем трещин) на примере трещиноватости в левосдвиговой разломной зоне (Западное Прибайкалье); $B, \Gamma$ - модель внутреннего строения мелкой $(B)$ и крупной $(\Gamma)$ (по [Seminsky, 2015] с изменениями) разломной зоны в разрезе. 1 - слабонарушенный породный массив; 2-4 - главные элементы внутреннего строения разломной зоны: 2 - периферийная подзона парагенетически связанных трещин, 3 - подзона разрывов 2-го порядка и повышенной трещиноватости (damage zone), 4 - подзона главного сместителя (fault core); 5 - внешняя граница разломной зоны.

Fig. 3. Fracture systems in fault zones.

$A, B$ - systematic $(A)$ and chaotic $(E)$ systems (circle diagrams; same numbers show triplets of joint sets) - fracturing in the left-lateral strike-slip fault zone, West Pribaikalie; $B, \Gamma$ - models showing the internal structure of the zones of small $(B)$ and large $(\Gamma)$ faults (cross sections after [Seminsky, 2015], modified). 1 - slightly fractured rocks; 2-4 - main components of the internal structure of the fault zone: 2 - peripheral subzone of paragenetically related fractures, 3 - subzone of the $2^{\text {nd }}$ order joints and higher fracturing (damage zone), 4 subzone of the main fault plane (fault core); 5 - outer boundary of the fault zone.

тектонически активных регионах - около $10 \%$ от общего числа [Burzunova, 2014]. Значительно чаще в таких районах формируется сложная хаотическая (по [Chernyshev, 1983]) сеть путем последовательного наложения двух и более троек систем тектонических трещин друг на друга (рис. 3, Б). Это происходит при изменении напряженного состояния (разнотипные второстепенные поля напряжений) в зоне одного крупного разломного сместителя и, кроме того, в результате совмещения зон влияния соседних разломов в массиве горных пород. При этом более нарушенные [Lobatskaya, 1987; Sherman et al., 1992; и дp.], вследствие, как правило, большей активности, висячие крылья разломов отличаются более сложными трещинными сетями [Burzunova, 2014].

Разработанный для анализа сложных приразломных сетей трещин новый методический подход заключается в сравнении природной трещинной сети с эталонными разрывными сетями, в состав которых входят тройственные парагенезисы. Исходным материалом для анализа служат статистические массовые замеры элементов залегания повсеместно распространенных «немых» трещин в горных породах, представленные в виде круговых диаграмм (стереограмм) в изолиниях плотности полюсов трещин (см. рис. $1, B$ ).

Эталонные сети трещин (эталоны) - это модели трещинных сетей в зонах скалывания разломного типа, составленные в результате обобщения теоретических, экспериментальных и природных закономерностей разрывообразования для трех основных типов динамических обстановок - сжатия, сдвига и растяжения [Seminsky, 2003]. Эталон включает главный разломный сместитель 1-го порядка и семь направлений опережающих мелких разломов 2-го порядка (R-, t-, n-, Т-типа), а также соответствующие каждому из них (и, в свою очередь, являющиеся для них структурами 2-го порядка) парагенезисы еще более мелких разрывов в виде троек систем опережающих трещин. Опережающими называют разрывы 2-го порядка, образованные до формирования разрыва 1-го порядка, вне зависимости от ранга. Главная система в тройке совпадает по ориентировке со «своим» мелким или крупным разломом.

Эталоны составлены для основных морфогенетических типов разломных зон (сброс, правый и 

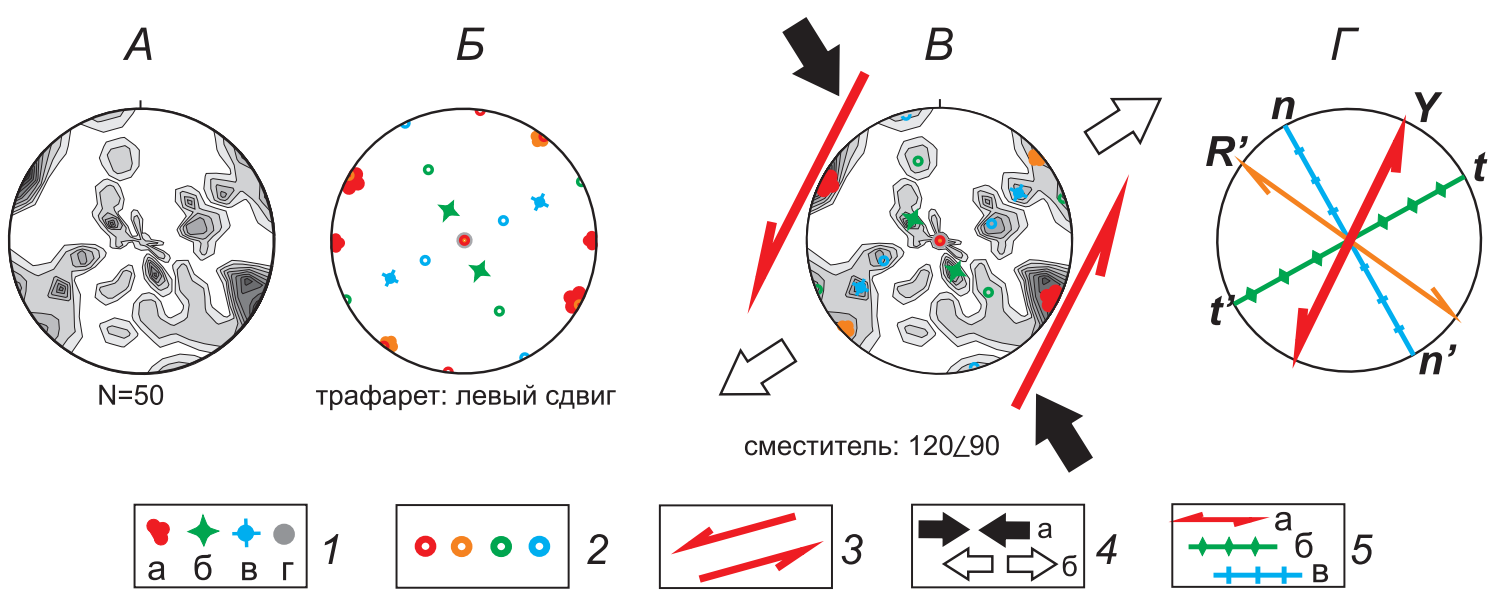

Рис. 4. Структурно-парагенетический анализ круговой диаграммы и его результаты на примере трещинной сети из левосдвиговой разломной зоны.

$A, 5$ - природная $(A)$ и эталонная $(Б)$ трещинные сети; $B$ - итоговое решение о динамической обстановке левого сдвига; $\Gamma$ структурные элементы зоны скалывания. 1 - полюсы главных систем трещин, соответствующих разломам 2-го порядка - сдвигу (а), взбросу (б) и сбросу (в), трансформационному (г); 2 - полюсы второстепенной и дополнительной систем трещин; 3 - положение левосдвиговой зоны, в которой формировались системы трещин, представленные на диаграмме; 4 - направление действия осей главных нормальных напряжений сжатия (а) и растяжения (б); 5 - простирание главного сместителя (Y) и разломов 2-го порядка (R-, t- и n-серий) - сдвигов (а), взбросов (б) и сбросов (в) в зоне скалывания.

Fig. 4. Structural-paragenetic analysis of the circle diagram and its results. Example: fractures in the left-lateral strike-slip fault zone.

$A, E$ - natural $(A)$ and standard $(E)$ joint systems; $B$ - final solution on the dynamic setting of the left-lateral strike-slip fault; $\Gamma$ - structural components of the shear zone. 1 - poles of the main joint sets corresponding to the $2^{\text {nd }}$ order faults - strike-slip (a), reverse (б), normal (в), transform (г); 2 - poles of the secondary and supplementary joint sets; 3 - position of the left-lateral strike-slip zone (its joint sets are shown in the diagram); 4 - direction of the main normal stress axes of compression (a) and extension (б); 5 - strike of the main fault plane $(\mathrm{Y})$ and the $2^{\text {nd }}$ order faults (R-, t- and n-series) - strike-slip (a), reverse (б) and normal (B) faults in the shear zone.

левый сдвиг, взброс, надвиг) с разными углами падения сместителей разломов [Seminsky, 2014]. Поскольку эталон является усредненной моделью сети трещин, его можно использовать при анализе трещиноватости в различных регионах.

Для сравнения и сопоставления с диаграммами природных трещинных сетей (рис. 4, A) каждый эталон представлен в виде кругового трафарета в равноугольной проекции верхней полусферы (рис. 4, Б), на котором значками показаны полюсы плоскостей магистрального сместителя, второстепенных разломов и троек систем трещин. Наиболее подходящий для диаграммы эталон по совокупности совпадающих систем трещин определяет решение: ориентировку и морфогенетический тип зоны скалывания (разломной зоны) локального ранга и структур 2-го порядка, а также поле напряжений, в котором сформировалась трещинная сеть (рис. $4, B, \Gamma$ ). Для одной диаграммы может быть получено 1-3 решения, иногда более.

Метод позволяет восстановить напряженное состояние локального объема горных пород для одного коренного выхода и установить его принадлежность к зоне локального разлома. Кроме того, используя сеть пунктов наблюдения и принципы генетической соподчиненности, в ходе порангового анализа можно перейти на региональный уровень с выделением местоположения и границ разломных зон, а также типа и ориентировки соответствующих полей напряжений.

Последовательность работ при спецкартировании разломной структуры разбита на три этапа подготовительный, обработки, интерпретации [Seminsky, 2015]. Наиболее важным является грамотное проведение работ подготовительного этапа (сбор данных в поле), а также первых стадий этапа обработки (сравнение природных трещинных сетей с эталонными на локальном уровне), так как это служит базой для дальнейшего анализа на региональном уровне. При выполнении этих начальных работ встречаются трудности, связанные с необходимостью корректного подбора исходных данных и новизной методических действий. Исходя из опыта применения методики в Прибайкалье и Монголии, далее в статье рассмотрены практические особенности первых этапов и приемы, призванные разрешить затруднения, возникающие наиболее часто. 


\section{3. ОСОБЕННОСТИ ПОДГОТОВИТЕЛЬНОГО ЭТАПА}

Подготовительный этап включает сбор полевых данных в виде статистических замеров элементов залегания трещин и геолого-структурного описания коренных выходов.

Основные приемы непосредственно сбора информации (п. 3.2) в некоторых деталях отличаются от стандартных способов, что продиктовано спецификой метода. Кроме того, в полевых условиях большое значение имеет выбор трещин, подходящих для измерений в качестве исходного фактического материала. Необходимо выявить соответствующие сети трещин среди многообразия разрывов, обусловленного разным происхождением.

Структурно-парагенетический метод разработан для изучения сложных приразломных трещинных сетей, состоящих в основном из тектонических разрывов, что является ключевым моментом подбора данных. В связи с этим наиболее эффективно применять методику в тектонически активных (или бывших ранее активными) регионах, где доминирующими силами, влияющими на формирование трещин, были тектонические, а другие силы и напряжения - стяжения (первичные трещины) или ротационные (планетарные трещины) - имели подчиненное значение. Такими регионами являются складчатые пояса, где вследствие высокой плотности разломов, зоны влияния которых, накладываясь друг на друга, занимают фактически всю площадь, широко развита тектоническая трещиноватость, что позволяет использовать метод почти повсеместно. В платформенных районах выбор участков работ требует особого внимания.

Кроме тектонических трещин, в породном массиве могут быть развиты другие типы трещиноватости, частично или слабо связанные с тектоническими напряжениями. Рассмотрим различные генетические типы трещин с точки зрения возможности использования их в новом подходе.

\section{1. ТИПЫ ТРЕЩИНОВАТОСТИ}

Трещиноватость тектонического происхождения имеет характерные признаки, по которым ее несложно идентифицировать в обнажении горных пород на стадии сбора исходного материала.

Прежде всего, согласно геометрической классификации С.Н. Чернышева [Chernyshev, 1983] определяется тип трещинной сети. Сфероидальные и полигональные сети с узнаваемой структурой (рис. 5) (шаровая, скорлуповатая или столбчатая отдельность) не рассматриваются в качестве объекта для нового вида анализа, так как сложены первичными, гипергенными или техногенными трещинами. Тектонические трещины группируются в систем- ную либо хаотическую сеть (рис. 5). Системная сеть представляет несколько различно ориентированных отчетливых систем трещин в породном массиве (см. рис. $3, A$ ), а хаотическая - более десяти систем [Chernyshev, 1983; Burzunova, 2014]) (см. рис. 3, Б) разной плотности. Следует помнить, что сеть тектонического происхождения, как правило, имеет не менее трех систем трещин [Chernyshev, 1983; Seminsky, Gladkov, 1991; Burzunova, 2014; u дp.]. Одна-две системы в трещинной сети свидетельствуют, скорее всего, о нетектоническом генезисе.

Кроме геометрии трещинной сети, оцениваются известные признаки тектонических трещин: сколовый тип, прямолинейность, относительная протяженность, пересечение структурных и вещественных границ, закономерная ориентировка в зоне разлома, наличие следов смещения (тектоническая глинка трения или брекчии, штрихи и зеркала скольжения, смещение маркеров) [Nevsky, 1979; Chernyshev, 1983; и др.]. Для мелких трещин хаотической сети вблизи разлома без следов смещений основным показателем является сколовый тип.

Трещины скалывания представлены правильными геометрическими плоскостями с ровными сглаженными стенками (рис. 6). В редких случаях в местах переслаивания пород с различной вязкостью развиваются дуговидные трещины скалывания с первичной кривизной [Gzovsky, 1975]. Поверхность трещин отрыва, напротив, неровная, шероховатая с множеством выступов и углублений. Трещины отрыва могут быть обусловлены и тектоническими, и нетектоническими силами. В первом случае доля их в трещинной сети небольшая (по подсчетам В.А. Невского - 0-15 \%), во втором нетектоническая сеть может полностью состоять из отрывов. Трещины отрыва широко развиты на поверхности, а трещины скалывания распространяются на большие глубины, занимая в целом господствующее положение в земной коре, в том числе и в разломных зонах.

Морфологические особенности трещин скола и отрыва зависят от структуры и текстуры пород. Например, отрыв в пегматитах будет более рельефным, чем в кварците, а в плотных тонкозернистых породах с равномерной структурой различия между сколами и отрывами в значительной мере сглаживаются [Nevsky, 1979] (рис. 6, A). Кроме того, на морфологию трещин скалывания оказывает влияние величина главных нормальных напряжений. Приповерхностные сколы формируются с дополнительным растяжением перпендикулярно плоскости разрыва (hybrid shear fructure [Hancock, 1985; Ramsey, Chester, 2004]), т. е. при транстенсивном скалывании. Их поверхность шероховатая и менее ровная, приближающаяся по внешнему виду 


\begin{tabular}{|c|c|c|c|}
\hline $\begin{array}{c}\text { Наименование } \\
\text { сети трещин } \\
\text { Name of fracture system }\end{array}$ & $\begin{array}{c}\text { Графическое изображение } \\
\text { Graphic image }\end{array}$ & $\begin{array}{c}\text { Пример трещинной сети } \\
\text { Example of fracture system }\end{array}$ & $\begin{array}{c}\text { Место реализации } \\
\text { Place of realization }\end{array}$ \\
\hline Сфероидальная & & & $\begin{array}{l}\text { в шаровых лавах, } \\
\text { в зоне выветривания, } \\
\text { при взрыве }\end{array}$ \\
\hline Spheroidal & & & $\begin{array}{l}\text { in pillow lava, weathering zone, } \\
\text { during blasting operations }\end{array}$ \\
\hline $\begin{array}{l}\text { Полигональная, } \\
\text { осесимметричная }\end{array}$ & & & $\begin{array}{l}\text { в трещинах столочатои } \\
\text { отдельности эфффузивов, } \\
\text { трещинах усыхания } \\
\text { осадочных слоев }\end{array}$ \\
\hline Polygonal & & & $\begin{array}{l}\text { columnar jointing in effusive rocks, } \\
\text { contemporaneous joints in } \\
\text { sedimentary rocks }\end{array}$ \\
\hline $\begin{array}{c}\text { Системная, } \\
\text { равноугольная }\end{array}$ & & & $\begin{array}{l}\text { у разрывов, на складках } \\
\text { продольног сжатия, в зоне } \\
\text { эрозионной разгрузи и др., } \\
\text { наиболее распространенная } \\
\text { сеть в массивах }\end{array}$ \\
\hline Systematic & & & $\begin{array}{l}\text { in flattened folds, } \\
\text { release joints in erosion zone et al., } \\
\text { prevalent fructure systems }\end{array}$ \\
\hline $\begin{array}{c}\text { Хаотическая, } \\
\text { асимметричная }\end{array}$ & & & $\begin{array}{l}\text { в зонах дробления, у разрывов, } \\
\text { у контакта интрузивов, } \\
\text { в зоне выветривания, } \\
\text { т.е. в наиболее подвижных } \\
\text { частях земной коры }\end{array}$ \\
\hline Chaotic & & & $\begin{array}{l}\text { in fault zones, crush belts, } \\
\text { shatter zones, } \\
\text { i.e. in crust mobile belts }\end{array}$ \\
\hline
\end{tabular}

Рис. 5. Основные типы трещинных сетей (по [Chernyshov, 1983] с изменениями, фото трещин выветривания в габбро и контракционных трещин в базальтах (сфероидальная и полигональная сеть) по [Tevelev, 2011]).

Fig. 5. Main types of joint systems (after [Chernyshov, 1983] modified. Photos: weathering fractures in gabbro and contraction joints in basalts (spheroidal and polygonal sets) (after [Tevelev, 2011]).

к отрывным трещинам. Глубинные трещины скалывания, образованные при транспрессивном скалывании, - ровные и гладкие даже без признаков смещений; в некоторых случаях они подобны поверхности распиленного образца горной породы. Такие классические сколы (shear fracture, shear joint) доминируют в разломных зонах [Sibson, 1998] (рис. 6, Б).

Относительно природы литогенетической и контракционной первичной трещиноватости необходимо учитывать важную особенность. На первоначальное формирование трещин в интрузивных и осадочных породах в условиях всестороннего сжатия, особенно в тектонически активных регионах, существенное влияние оказывают напряженное состояние и динамическая обстановка в прилегающих массивах (подвижность «тектонической рамы»), что отмечено в известных работах А.А. Полканова, Г.Д. Ажгирея, С.Н. Чернышева, Ю.Г. Леонова, Т.П. Белоусова. Кроме того, об этом свидетельствуют исследования трещин в керне осадков озера Байкал [Seminskii et al., 2001b], в породах интрузивного сиенитового массива в Приольхонье [Burzuno$v a, 2015]$ и осадочного чехла Сибирской платформы [Seminskii et al., 2001a]. Генезис таких трещин неоднозначен, поскольку они возникают под воздействием не только внутренних сил, но и внешних напряжений. Тем не менее наличие соответствующих вышеназванных признаков допускает применение структурно-парагенетического метода. 


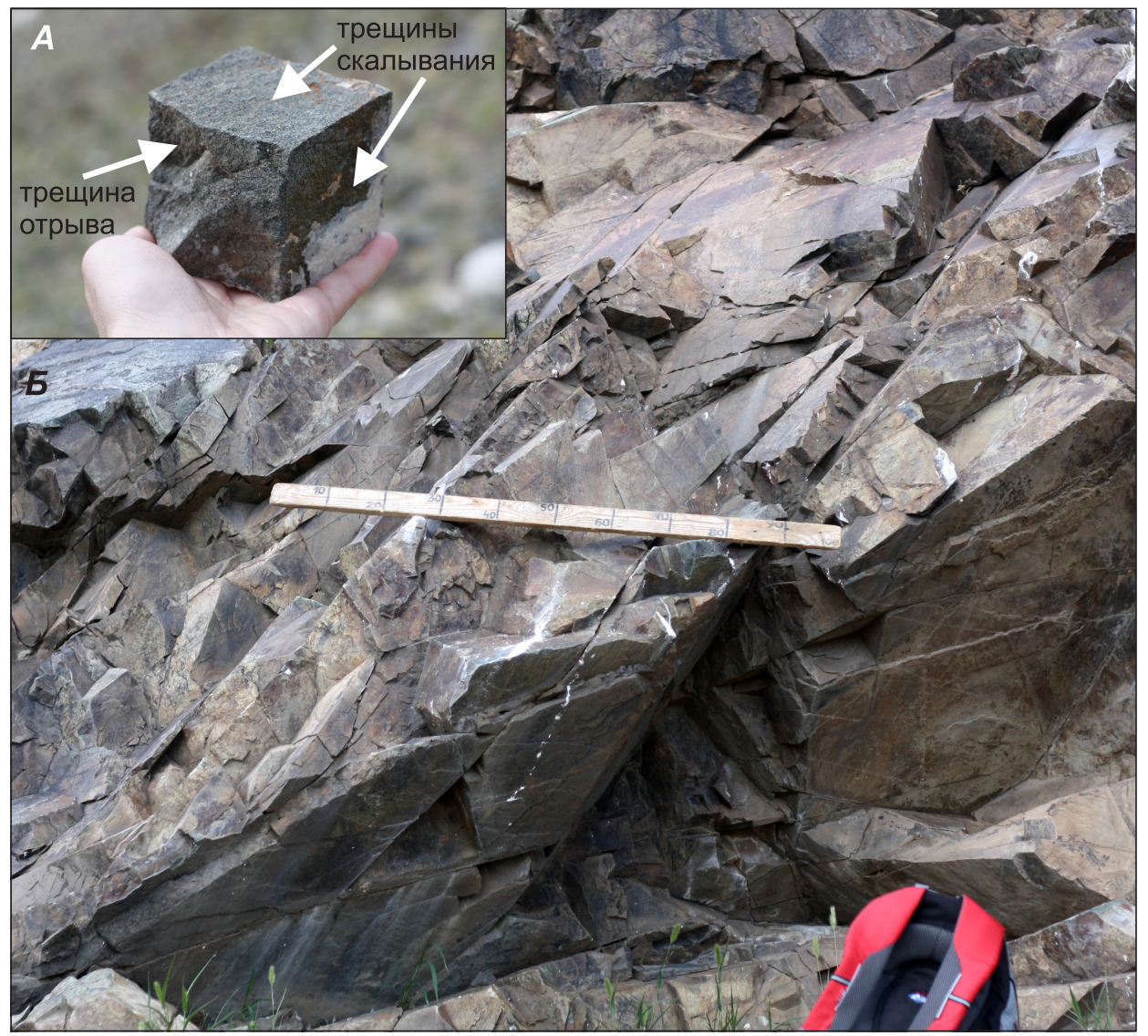

Рис. 6. Трещины скалывания и отрыва в горных породах.

$A$ - трещины кубической отдельности в разгнейсованном габбро (Прибайкалье); 5 - коренной выход с преобладанием трещин скалывания в породах кремнисто-терригенного комплекса (Центральная Монголия) (масштабная линейка на фото равна 1 м).

Fig. 6. Shear and extension joints in the rocks.

$A$ - joints of cubical separation in gneiss gabbro (Pribaikalie); $E$ - host rock outcrop with dominating shear joints in siliceous terrigenous rocks (Central Mongolia). Photo: scale bar $=1.0 \mathrm{~m}$.

Планетарные трещины имеют двойственную природу - внутренние силы стяжения при литификации пород или остывании расплава являются причиной образования разрывов, а внешние - ротационные напряжения - задают их закономерную ориентировку. Ротационные напряжения значительно слабее тектонических, поэтому в складчатых поясах планетарная трещиноватость проявлена слабо и методом парагенетического анализа не изучалась.

В зоне гипергенеза большая часть трещин наследуется от первичных или тектонических трещин, которые можно различить визуально в обнажении горных пород. Первичные трещины (сфероидальные и полигональные сети трещин отрыва) в методике не используются. Тектонические трещины (системные и хаотические сети трещин скалывания) могут находиться в скрытом состоянии длительное время, пока не окажутся в зоне выветривания и низких давлений, где они расширяются, становятся видимыми. При этом увеличивается общая плотность трещин, а их основные ориентировки сохраняются [Chernyshev, 1983], что позволяет применять метод. Исключением являются участки с интенсивным выветриванием, где преобладают новообразованные гипергенные трещины отрыва [Chernyshev, 1983; Mikhailov, 1984]. Такие трещинные сети не входят в геометрическую классификацию и не имеют характерных для них типичных структур, кроме сфероидальной сети (см. рис. 5). То же относится к применимости метода для анализа техногенных трещин, связанных с инженерной деятельностью человека, которые являются унаследованными и (или) новообразованными. Наличие последних следует учитывать при исследованиях разрывов в горных выработках и вблизи объектов строительства.

В горных породах встречаются также трещины, образованные по плоскостям кливажа. Трещины по кливажу складчатости не используются в анализе. 
Приразрывный кливаж [Mikhailov, 1984], или кливаж синтектонической сланцеватости [Goncharov et al., 2005], образуется в разломных зонах (кливаж разлома) [Sherman, 2002], где по ослабленным плоскостям развиваются затем тектонические трещины, которые можно применять в анализе.

При наличии трещин разного происхождения используется комплексный подход с разделением их по генезису. Смешанная трещинная сеть анализируется, если в ней имеются тектонические трещины (чем больше их доля, тем достовернее результаты). Трещинные сети явно нетектонического происхождения (полностью отрывного типа) первичные трещины столбчатой отдельности, послойные или бессистемные внутрислойные трещины отрыва, ориентированные беспорядочно либо согласно поверхностям коренных выходов трещины выветривания, - исследовать новым методом, ориентированным на тектоническую трещиноватость, не имеет смысла.

Метод разрабатывался для трещин в скальных породах, однако он успешно опробован сотрудниками лаборатории тектонофизики ИЗК СО РАН для осадочных слабосцементированных кайнозойских пород в зоне Ангарского разлома и на территории Байкальского рифта, где проявлены отчетливые тектонические трещины скола и отрыва, смещения слоев и сколы гальки [Seminskii et al., 2001a; Seminsky, Cheremnykh, 2011]. Значимость таких исследований заключается в возможности охарактеризовать последние этапы тектонического развития района.

Таким образом, структурно-парагенетический метод изучения трещиноватости можно использовать как в интрузивных телах и осадочном чехле, так и в зоне гипергенеза и слабосцементированных породах. Особенно результативно методика применяется в районах с высокой тектонической активностью. Основным признаком трещин тектонического происхождения является системная или хаотическая (многосистемная) структура сети сколового типа, наличие которой рекомендуется оценить в первую очередь. Чем выше процентное содержание тектонических трещин в обнажении горных пород, тем больше информации можно получить для структурно-парагенетического анализа.

\section{2. СБОР ФАКТИЧЕСКОГО МАТЕРИАЛА}

Приемы сбора исходных геолого-структурных данных определяются, с одной стороны, общими рекомендациями (Г.Д. Ажгирей, А.Е. Михайлов, В.А. Невский, П.Н. Николаев и мн. др.), с другой полученным практическим опытом использования нового подхода к структурно-парагенетическому анализу трещин [Seminsky, 2015]. Пункты наблюде- ний располагаются равномерно по площади либо на специально выбранных участках (например, по профилям в крест простирания разломной зоны). Их заданное количество и местоположение корректируются условиями обнаженности горных пород и сложностью геологического строения.

В каждом пункте наблюдения проводятся массовые замеры элементов залегания трещин. Площадка для замера должна быть однородной по структурно-вещественным свойствам. Отдельно проводится замер на участках, различающихся по степени нарушенности горных пород трещинами или по разновидности сети (подзоны в разломной зоне), типу горных пород, геологическому строению (крылья складки, геологические тела). Площадка должна иметь по возможности три различно ориентированные поверхности, чтобы выявить все развитые на данном участке системы, так как трещины, параллельные поверхности обнажения, обычно недостаточно представлены в выборке. В случае коренного выхода значительной протяженности следует внимательно выбирать интервал для массового замера, предпочитая участки с преобладанием тектонических трещин с относительно «свежими» отдельностями, не разрушенными процессами выветривания.

Для решения вопросов происхождения большинства разрывов в коренном выходе необходимо получить информативную диаграмму, для чего на выбранной площадке следует измерять все трещины подряд, без пропусков [Nevsky, 1979]; при этом замер каждой последующей трещины должен существенно отличаться от предыдущего по ориентировке. Это позволяет получать более объективные измерения, исключая субъективный выбор «удобных» плоскостей, и, кроме того, является важным для единообразия измерений разными специалистами. Значения элементов залегания не округляются, чтобы избежать потери точности структурного рисунка на диаграмме.

Кроме элементов залегания отмечаются значимые вспомогательные для анализа данные: тип трещин (скол или отрыв), ранг (или размер), при наличии - признаки сопряженности [Gzovsky, 1975], вторичная минерализация на стенках, следы смещений. Это помогает сгруппировать трещины на диаграмме для дальнейшего анализа условий их развития и возраста, уточнить морфогенетический тип разрывов, а также подтвердить наличие тройственного парагенезиса. В тройке две системы являются сколовыми, а третья, первоначально формируясь как отрыв, вместе с тем может иметь следы подвижек, компенсирующих смещения по первым двум сколам [Seminsky, 2003]. Если при массовых замерах встречается трещина значительно крупнее остальных (на один-два порядка), 
$A$

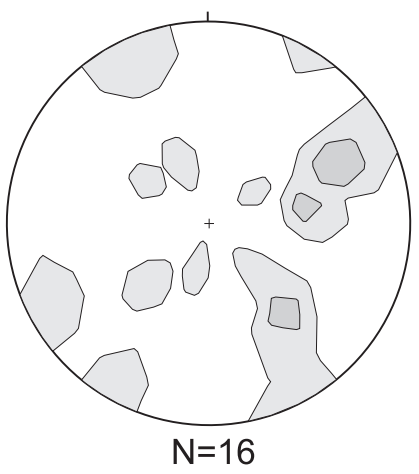

B

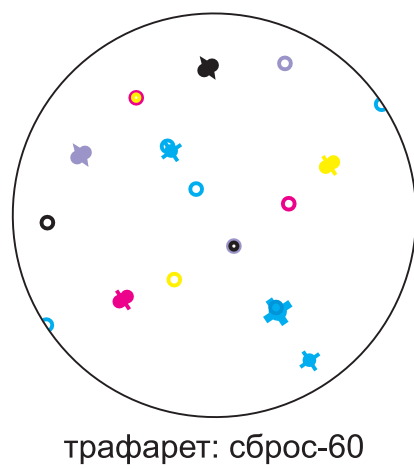

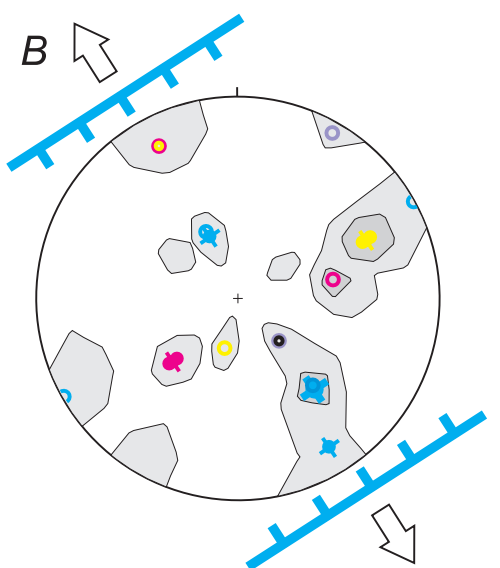
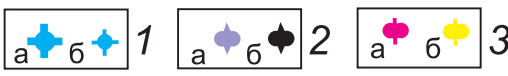

\begin{tabular}{ccc}
\hline 0 & 0 & 0 \\
0 & 4
\end{tabular}

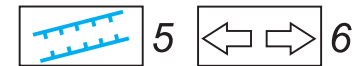

Рис. 7. Анализ круговой диаграммы трещиноватости с малым количеством замеров (Приольхонье).

$A$ - круговая диаграмма, построенная для 16 крупных (длина более 1.5 м) сколовых трещин (уровни изолиний 6 \%, $12 \%$ ); 5 эталонный парагенезис сброса; $B$ - итоговое решение о динамической обстановке растяжения. 1 - полюсы главной системы трещин, соответствующей сбросовому разлому 1-го (а) и 2-го (б) порядка; 2-3 - полюсы главных систем трещин, соответствующих разломам 2-го порядка: 2 - правый (а) и левый (б) взбросо-сдвиг, 3 - правый (а) и левый (б) сдвиго-сброс; 4 - полюсы второстепенной и дополнительной систем трещин; 5 - положение зоны сброса локального ранга, в которой формировались сколовые трещины; 6 - направление действия оси главного нормального напряжения растяжения.

Fig. 7. Analysis of the circle fracture diagram with a small number of measurements (Olkhon area).

$A$ - circle diagram for 16 large (over $1.5 \mathrm{~m}$ long) shear joints (levels of isolines: $6 \%, 12 \%$ ); $E$ - standard paragenesis of the normal fault; $B$ - final solution on the dynamic setting of extension. 1 - poles of the main joints set corresponding to the $1^{\text {st }}$ (a) and $2^{\text {nd }}$ (б) order faults; 2-3 - poles of the main joint sets corresponding to the $2^{\text {nd }}$ order faults: 2 - right- (a) and left-lateral (б) strike-slip fault with reverse component; 3 - right- (a) and left-lateral (б) normal fault with strike-slip component; 4 - poles of the secondary and supplementary joint sets; 5 - position zones of the local normal fault zone with shear joints; 6 - direction of the axis of the main normal extension stress.

то сведения о ней используются как признак поля напряжений большего ранга. Очень мелкие разрывы (длиной 1-2 см) измеряются в случаях, когда обнажение горных пород небольших размеров не представлено необходимым количеством трещин.

Для сравнения диаграмм между собой предпочтительно использовать одинаковые по числу разрывов замеры. Оптимальное количество трещин для одного замера, позволяющее зафиксировать все направления в локальном объеме горных пород на уровне одного обнажения, - 100 штук. При малом их количестве не отмечаются менее проявленные системы, а слишком большое количество трещин в замере приводит к перегруженности рисунка диаграммы и объединению максимумов, к увеличению площадки замера и вероятности «попасть»в другое локальное поле напряжений. По этой же причине не рекомендуется использовать в ходе структурно-парагенетического анализа для сравнения с эталонами сводные или синоптические диаграммы трещиноватости, применяемые в структурной геологии для выделения рангов разрывов или их доминирующих направлений на больших площадях. Опыт показал, что в тектониче- ски активных регионах такие диаграммы представляют сплошное поле полюсов трещин в результате объединения множества разнотипных и разноориентированных парагенезисов, которые практически невозможно разделить качественно.

Размер площадки для массового замера зависит от плотности трещин (обычно не более $10 \mathrm{~m}^{2}$ ). Если коренной выход небольшой и число разрывов недостаточно, замер производится только при наличии четких сколовых трещин. Даже при малом их количестве (10-20 штук) эти направления могут послужить дополнительным подтверждением достоверности выделения парагенезисов в соседних точках (рис. 7).

Кроме массовых замеров, стандартно документируются структурные и геологические особенности коренного выхода, которые учитываются при интерпретации результатов анализа (раздел 4.1. подп. 3). В случае недоступного для прямого изучения сместителя разлома или его отсутствия на первой стадии развития разломной зоны или неимения признаков смещений структура сети опережающих трещин служит единственным источником информации, что является одним из достоинств метода. 
Рассмотренные приемы проведения геологоструктурных наблюдений должны быть едиными для всех пунктов. Этого требует статистический характер исходных материалов и их дальнейшая однотипная обработка, а также сравнение решений между собой. Увеличение общего числа пунктов наблюдения повышает достоверность полученных решений по зонам скалывания и полям напряжений, то есть в целом эффективность метода возрастает.

\section{4. ОСОБЕННОСТИ ЭТАПА ОБРАБОТКИ}

Этап обработки является главным, так как его конечный итог представляет последовательно восстановленные разломные зоны и поля напряжений разных масштабных уровней.

Первая стадия этапа обработки включает построение стандартных для структурной геологии круговых диаграмм трещиноватости (см. рис. 1, B) и выявление простых трещинных парагенезисов. Ниже кратко перечислены основные параметры построений.

Процесс автоматизирован в различных программных комплексах. При этом в рамках структурно-парагенетического метода используются: стереографическая равноугольная проекция Вульфа (верхняя полусфера), палетка Пронина со скользящим окном-ячейкой, равным $10^{\circ}$, расчет изолиний в процентах, поправочные коэффициенты для максимумов [Seminsky, 2015]. Максимумы в местах сгущения изолиний представляют системы трещин, центр максимума фиксирует среднее значение угла и азимута падения трещин данной системы. Интенсивность (или плотность) максимума показывает максимальное количество трещин (в пределах окна палетки) системы, выраженное в процентах к общему количеству.

Метод не предусматривает выделение систем трещин путем удаления изолиний низкой интенсивности, чтобы не снижать информативность диаграммы. К анализу привлекаются все максимумы, в том числе самой низкой интенсивности (1-2 трещины), которые согласно базовой статистике замера (100 трещин) формально не могут считаться системой. Однако в ряде случаев такой максимум представлен крупной трещиной или плоскостью со штрихами скольжения, что является значимой информацией для структурно-парагенетического анализа. Подобный максимум в другом масштабе изучения (при большей площадке для массового замера) может быть полноценной системой.

Далее проводится оценка взаимного расположения и интенсивности максимумов (систем трещин) на диаграммах, выделяются тройки (одна или несколько) примерно перпендикулярных систем трещин.

Вторая стадия этапа обработки является наиболее важной, поскольку включает первоначальную интерпретацию трещиноватости непосредственно локальных выходов горных пород. В ходе сравнительного анализа природных диаграмм с эталонными трафаретами необходимо с высокой степенью надежности провести реконструкцию локальных разломных зон и полей напряжений (см. рис. 4), которые служат основанием для последующего восстановления региональных зон и полей напряжений на третьей и четвертой стадиях этапа обработки [Seminsky, 2015] (в данной статье не рассматриваются).

\section{1. СРАВНЕНИЕ С ЭТАЛОННЫМИ ТРЕЩИННЫМИ СЕТЯМИ}

Рассмотрим особенности практической реализации сравнительного анализа трещинных сетей. Технически сопоставление диаграмм (рис. 8) удобно проводить с помощью векторного графического редактора Corel Draw с применением разных слоев.

Эталонный идеализированный парагенезис является универсальной моделью тектонической сети трещин. Для того чтобы максимально соответствовать большинству природных ситуаций, эталон включает все возможные опережающие разрывы в разломной зоне; кроме того, имеет усредненные угловые величины между системами трещин. Тем не менее ввиду разнообразия природных условий деформации в трещинных сетях обычно проявлена часть систем эталонного трафарета и имеются отклонения систем от эталонного положения (примеры сравнительного анализа на рис. 8).

При сравнении диаграммы с трафаретами используются следующие особенности и приемы анализа диаграмм, которые сводят до минимума ошибки случайного «механического» совпадения систем трещин с эталонами.

1. Специфический структурный рисунок эталонной диаграммы - совокупность троек систем трещин, представляющий группу определенным образом взаимно ориентированных максимумов (рис. 8, I). Идентификация тройки систем на диаграмме трещиноватости дает более надежные результаты по сравнению, например, с парой предполагаемых сопряженных систем (метод М.В.Гзовского), для которой на сложной хаотической диаграмме будет значительно больше вариантов возможных решений. Вероятность случайного совмещения сразу нескольких троек еще меньше, поэтому совпадение большинства максимумов с эталонными системами позволяет считать данное решение достоверным. При сопоставлении допускаются отклонения си- 

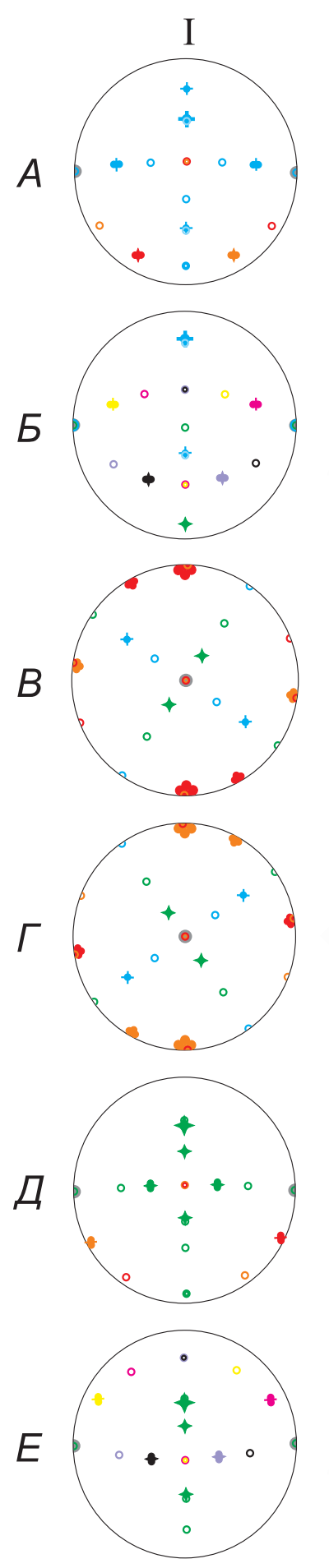
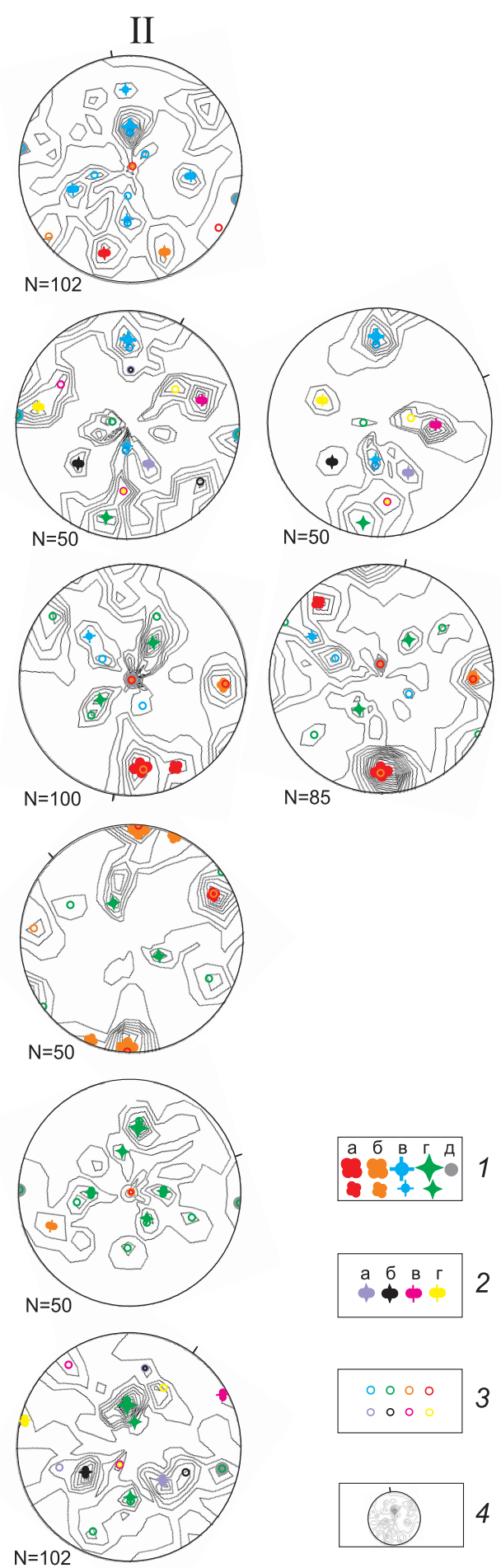

3

Рис. 8. Результаты сравнения круговых диаграмм трещиноватости с эталонными парагенезисами (на примере трещинных сетей Прибайкалья).

I - эталонные трафареты; II - решения. $A, B$ сброс; $B$ - левый сдвиг; $\Gamma$ - правый сдвиг; Д взброс; $E$ - надвиг. 1 - полюсы главных систем трещин, соответствующих разломам 1-го (крупные значки) и 2-го (мелкие значки) порядка: левого (а) и правого (б) сдвига, сброса (в), взброса (г), трансформационного (д); 2 - полюсы главных систем трещин, соответствующих разломам 2-го порядка: правый (а) и левый (б) взбросо-сдвиг или сдвиго-взброс, правый (в) и левый (г) сбрососдвиг или сдвиго-сброс; 3 - полюсы второстепенной и дополнительной систем трещин; 4 - направление на север на круговой диаграмме.

Fig. 8. The results of comparison of the circle fracture diagrams with the standard parageneses (example: joint systems in Pribaikalie).

I - standard sets; II - solutions. Faults: $A, B$ - normal; $B$ - left-lateral strike-slip; $\Gamma$ - right-lateral strike-slip; $Д$ - reverse; $E$ - thrust. 1 - poles of the main joint sets corresponding to the $1^{\text {st }}$ order (large symbols) and $2^{\text {nd }}$ order (small symbols) faults: left-lateral (a) and right-lateral (б) strike-slip, normal (в), reverse (г), transform (д); 2 - poles of the main joint sets corresponding to the $2^{\text {nd }}$ order faults: right- (a) and leftlateral (б) strike-slip fault with reverse component or reverse fault with strike-slip component, right- (в) and left-lateral ( $Г$ ) strike-slip fault with normal component or normal fault with strike-slip component; 3 - poles of the secondary and supplementary joint sets; 4 - direction to the north in the circle diagram.

стем трещин от эталонных ориентировок до $10^{\circ}$, в случаях главной и второстепенной систем возможен больший разброс.

2. Достоверность выбранного решения повышают количественные и качественные характеристики трещинной сети: угол между сопряженными системами в пределах статистически выявленных величин [Burzunova, 2011] (см. раздел 2), бо́льшая интенсивность систем тройки, принадлежащей главному сместителю, противоположные разбросы полюсов трещин у асимметричных максимумов сопряженных систем в сторону оси максимального сжатия (разбросы плоскостей трещин - в сторону оси минимального сжатия) [Nikolaev, 1992], распределение трещин скола и отрыва в системах тройки. Также рекомендуется строить дополнительные круговые диаграммы по трещинам только сколового типа (если их менее $80 \%$ ) и по трещинам крупного ранга (если их более $20 \%$ ), что помогает в расшифровке систем и определении решений. 
3. Геолого-структурная информация о коренном выходе - зоны повышенной трещиноватости, зоны тектонического рассланцевания, зоны тектонитов (глинка трения, тектоническая брекчия и др.), кинематические данные (штрихи скольжения, смещения маркеров) и др. Эти линейные и плоскостные структуры, совпадающие по ориентировке и кинематике с разрывами выбранного эталона и природными системами трещин, служат доказательством правомерности выбора соответствующих решений, что также повышает их достоверность.

4. Повторяемость - основной признак любого парагенезиса, проявляющийся при увеличении количества массовых замеров на участке исследования. Наличие одинаковых парагенезисов трещин в соседних пунктах наблюдения не случайно и свидетельствует о единой причине их формирования. Если же полученный одиночный парагенезис нигде более не встречается и не подтвержден геологоструктурными данными, допускается им пренебречь на данном этапе исследования участка.

Опыт показал, что в пределах тектонически активных участков земной коры в большинстве коренных выходов для одной трещинной сети определяется несколько первоначальных вариантов решений. Структурные и геолого-структурные данные (подп. 1-3) определяют уровень достоверности каждого решения. Если по этим критериям оценки два решения являются приблизительно равнозначными, принимаются оба. Дальнейшая оценка значимости решений проходит с учетом статистики подобных парагенезисов в соседних пунктах наблюдения (подп. 4).

Количество нерасшифрованных систем трещин на диаграммах, не вошедших в парагенезис при сравнении с эталонами, зависит от конкретного обнажения пород. Как правило, это одна или несколько систем небольшой плотности (рис. 8, II). Наличие таких систем может быть обусловлено разными причинами - оперяющими разрывами, трещинами других этапов деформации, нетектоническими разрывами и т.д.

Наиболее достоверные окончательные решения (обычно два-три) в результате анализа одной трещинной сети, выбранные с помощью критериев сравнения, свидетельствуют о разновозрастных напряженных состояниях, имевших место в процессе тектонического развития изучаемого участка земной коры.

\section{2. ВОПРОСЫ ИНТЕРПРЕТАЦИИ ПРИРОДНЫХ ТРЕЩИННЫХ СЕТЕЙ}

В процессе сравнительного анализа нередко появляются вопросы, вызванные разнообразным строением природных трещинных сетей и пород- ных массивов. Возникают сложности, обусловленные такими обстоятельствами, как значительное отклонение величин углов между системами трещин от эталонного значения, трещиноватость в разломных зонах смешанного морфогенетического типа, отличные от тройственного парагенезисы, наличие структурно-вещественных неоднородностей и их возможное влияние на рисунок диаграммы. Ниже последовательно рассмотрены перечисленные особенности интерпретации трещинных сетей.

При выделении на диаграммах троек взаимно ортогональных систем трещин особое внимание обращается на угловые соотношения между системами. Отклонения от прямого угла по разным причинам могут достигать $20^{\circ}$ и более, особенно между главной и второстепенной системами. Среднестатистические значения угла у сопряженных сколов в разных динамических обстановках [Burzunova, 2011] заложены в эталонные парагенезисы разных морфогенетических типов - сброс, сдвиг, взброс, надвиг, а размах вариаций (см. раздел 2) учитывается при сопоставлении диаграмм трещиноватости с эталонными трафаретами. Величины углов для соседних пунктов наблюдения используются в дальнейшем анализе для определения относительного возраста разрывных парагенезисов в связи с глубиной формирования сопряженных сколов.

Подавляющее большинство изучаемых в современном срезе тектонических трещин в разломных зонах возникло в условиях трехосного сжатия на глубине примерно от 2-3 до 10 км [Nikolaevsky, 2010]. Однако встречаются сети тектонических трещин, образованные в близповерхностном слое земной коры (с участием растягивающих напряжений). Их сопоставление с эталонами может быть менее точным, так как из трех систем тройственного парагенезиса могут присутствовать только две сопряженные системы сколов (см. рис. 2, A). Угол между ними всегда острый и, как правило, меньше среднего угла между сколами в тройке (например, на рис. 8, II, $\Gamma$ ) и в большой степени зависит от типа пород. В таких случаях необходимо раздельно анализировать сети трещин в породах, существенно различающихся по физико-механическим свойствам.

Наличие тройственного парагенезиса в трещинной сети зависит в целом от ее местонахождения тектонической активности региона, глубины ее формирования. В разломных зонах тройки трещинных систем по встречаемости резко преобладают над другими известными парагенезисами трещин со специфическими условиями образования (конусы, пояса, пирамиды и др.) [Seminsky, 2014]. Тем не менее в процессе структурно-парагенетического анализа можно интерпретировать 
частные разновидности поясов трещиноватости и пирамид скалывания.

Большая часть поясов трещиноватости принадлежит двум типам [Gladkov, Seminskii, 1999]. Пояса опережающих трещин, образованные наложением нескольких троек систем, имеются на эталонных трафаретах (рис. 8, I). Разбросы полюсов трещин у сопряженных систем такого пояса направлены в противоположные стороны [Nikolaev, 1992]. В отличие от него, пояс вращения обусловлен разворотом опережающих и оперяющих трещин при вращении материала в процессе смещения крыльев разлома [Danilovich, 1961]. Подобный пояс представлен на круговой диаграмме как совокупность «вытянутых» вдоль линии пояса максимумов с односторонними разбросами полюсов трещин, в этом случае применяется метод В.Н. Даниловича и его модификации.

Пирамида скалывания из двух пар сопряженных сколов [Rastsvetaev, 1987] формируется при переиндексации осей напряжений в условиях осесимметрического напряженного состояния (вторая пара сколовых систем - вместо дополнительной системы на рис. 2, Б) и на уровне трещин встречается редко. Что касается разрывов большего ранга, пирамида скалывания образуется в виде двух пар сопряженных мелких разломов 2-го порядка (в зоне крупного разлома 1-го порядка), каждый из которых на уровне трещиноватости представлен системой трещин (рис. 8), что позволяет анализировать их с помощью эталонных трафаретов.

Структурно-парагенетический метод не исключает исследование трещиноватости вблизи разломов смешанного морфогенетического типа, несмотря на то, что эталонные парагенезисы трещинных сетей составлены для разломных зон «чистых» типов (рис. 8, I). В целом при сравнении диаграмм с эталонами учитывается незначительная природная горизонтальная составляющая для сбросов и взбросов или вертикальная составляющая для сдвигов в пределах 20․ Смешанные типы разломов наблюдаются в редких случаях, они образованы при наклонном положении всех трех осей главных нормальных напряжений. Системы тройственного парагенезиса в этом случае располагаются примерно под углом 30-60 к горизонту, а анализ круговой диаграммы ограничивается оценкой одной основной тройки систем трещин (рис. 9, $A$ ) с рассмотрением возможных решений с учетом критериев достоверности (см. раздел 4.1. подп. 2-4). Мелкие разломы с комбинированным типом смещений встречаются чаще в качестве второстепенных в более крупных разломных зонах «чистого» типа (например, взбросо-сдвиги или сдвиго-сбросы в зонах растяжения на рис. 9, Б), они имеются в составе эталонных парагенезисов (см. рис. 8, I).
Следует упомянуть о структурно-вещественных неоднородностях, которые в определенной мере оказывают воздействие на формирование рисунка разрывной сети на диаграмме трещиноватости.

Влияние неоднородностей неразрывного типа при активно действующих тектонических напряжениях в горном массиве проявляется незначительно и локально. Анизотропия горных пород в большинстве случаев не определяет положение разрывов, а вносит в него некоторое дополнительное осложнение [Gzovsky, 1975]. Возможно снижение степени сложности сетей трещин, например, в линейно ориентированных метаморфических породах [Burzunova, 2014]. При реконструкции полей напряжений можно наблюдать их частичное искажение, но в целом при условии статистических площадных исследований на изучаемом участке проявляется общее региональное поле напряжений, о чем свидетельствуют результаты анализа трещиноватости Тажеранского интрузивного массива (Западное Прибайкалье) и вмещающих метаморфических слоистых толщ [Burzunova, 2013]. Вместе с тем широкое развитие трещин, не совпадающих с ослабленными поверхностями, свидетельствует о том, что во многих случаях направление разрывов определяется только действующими в нем напряжениями [Gzovsky, 1975]. Вновь образованные сколы могут формироваться под очень острым углом к линейным текстурным плоскостям, что было зафиксировано, например, на участке мыса Улирба в Прибайкалье.

Применение метода в специфических условиях, таких как наличие крупных складчатых форм залегания пород, требует дополнительных целенаправленных исследований. Возникает вопрос о целесообразности предварительного «приведения» пластов (залегание пород) к горизонтальному положению в ходе анализа диаграмм. Задачей структурно-парагенетического метода является расшифровка всей истории формирования разрывных нарушений на изучаемой площади, т. е. определение положения главных осей палеонапряжений не только до формирования складок, но и при более поздних деформациях. В этой связи следует проводить анализ диаграмм с выпрямлением слоев и без такового с последующим комплексным анализом парагенезисов трещин в крыльях и замках складок. С учетом соседних точек наблюдения и общей геологической структуры района это поможет выявить парагенезисы и поля напряжений разного возраста и уточнить строение участка.

Что касается структурных неоднородностей разрывного типа, поднимается вопрос об унаследованности более древних трещин и правомерности использования эталона в случае нескольких этапов деформации. Известно, что если существу- 

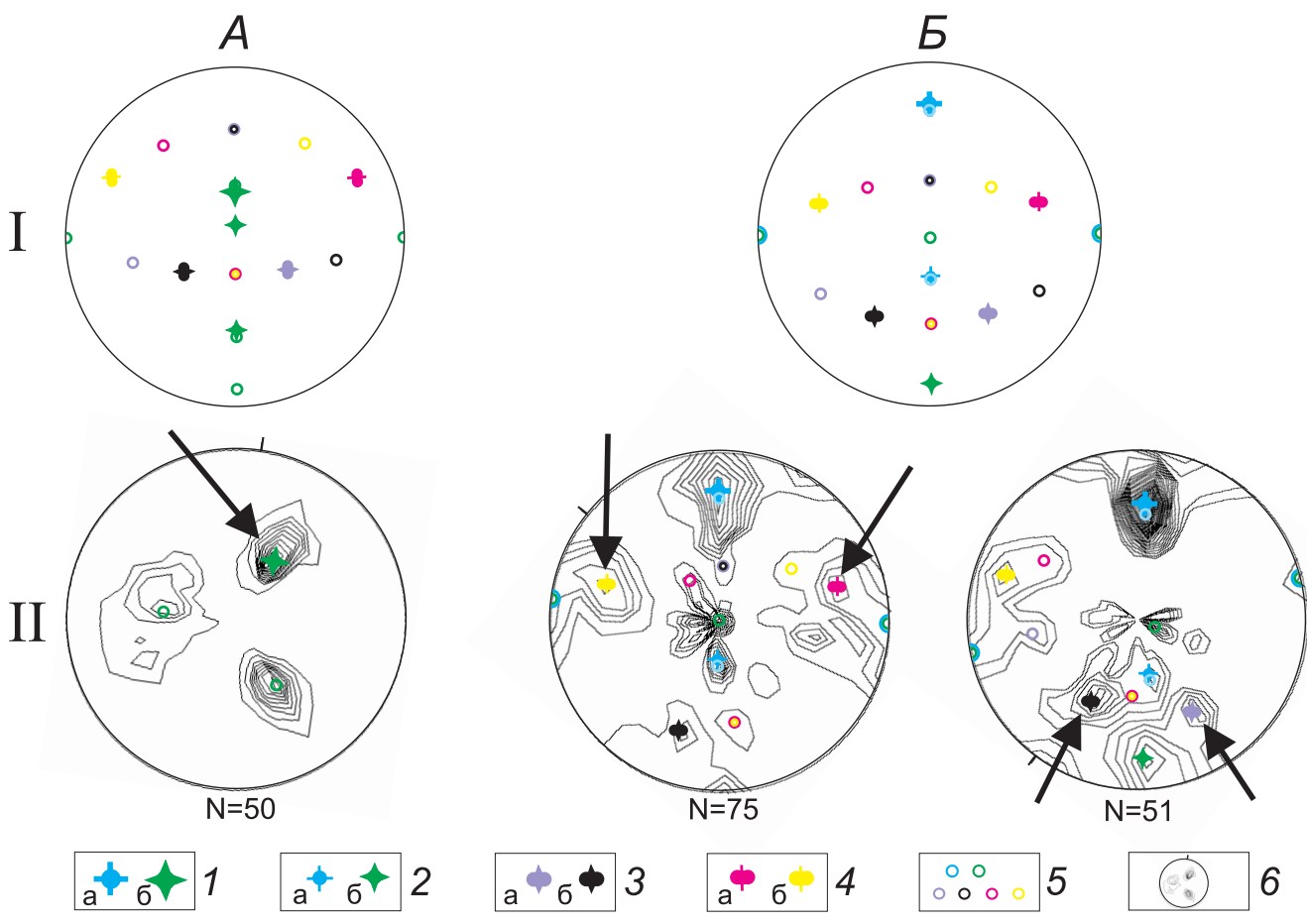

Рис. 9. Смешанные морфогенетические типы разломов по результатам анализа (указаны стрелками): правый сдвиго-надвиг 1-го порядка $(A, \mathrm{II})$, сдвиго-сбросы и взбросо-сдвиги 2-го порядка в решениях сброса 1-го порядка (Б, II).

I - эталонные парагенезисы надвига $(A)$ и сброса (Б); II - решения анализа диаграмм трещиноватости (Приольхонье). 1 - полюс главной системы трещин, соответствующей разлому 1-го порядка: сброс (а), надвиг (б); 2-4 - полюсы главных систем трещин, соответствующих разломам 2-го порядка: 2 - сброс (а), взброс (б), 3 - правый (а) и левый (б) взбросо-сдвиг, 4 - правый (а) и левый (б) сдвиго-сброс; 5 - полюсы второстепенной и дополнительной систем трещин; 6 - направление на север на круговой диаграмме.

Fig. 9. Mixed morphogenetic types of faults according to the analysis results (indicated by arrows): $1^{\text {st }}$ order right-lateral thrust with strike-slip component $(A, \mathrm{II}), 2$ nd order normal faults with strike-slip component and strike-slip faults with reverse component - solutions for the $1^{\text {st }}$ order normal fault $(5$, II).

I - standard parageneses of thrust $(A)$ and normal $(5)$ faults; II - solutions from the circle fracture diagrams (Olkhon area). 1 - poles of the main joint set corresponding to the 1 st order fault: strike-slip (a) and thrust (б) faults; 2-4 - poles of the main joint sets corresponding to the $2^{\text {nd }}$ order faults: 2 - normal (a) and reverse (б) faults, 3 - right- (a) and left-lateral (б) strike-slip fault with reverse component, 4 - right- (a) and left-lateral (б) normal fault with strike-slip component; 5 - poles of the secondary and supplementary joint sets; 6 - direction to the north in the circle diagram.

ющие разрывы удовлетворяют ориентировкам будущего нового разрыва, то происходит их активизация [Nevsky, 1979; Rastsvetaev, 1987]. В этом случае при проведении структурно-парагенетического анализа система трещин может участвовать в разных решениях. Уровень достоверности каждого из них определяется по вышеназванным критериям оценки диаграмм. Последующая статистическая обработка с привлечением всех точек наблюдения на участке исследования с учетом распространенности решений по площади помогает выделить разные этапы деформации, уверенно различающиеся по всем признакам, в том числе и по относительному возрасту [Burzunova, 2015]. Если ориентировки старых и новых разрывов не совпадают, активизации трещин может не быть, особенно на больших глубинах. В условиях всестороннего дав- ления трещины находятся в скрытом состоянии и не влияют на формирование новых в качестве ослабленных поверхностей. Об этом свидетельствует наличие множества систем тектонических трещин на одной диаграмме (см. рис. $3,5,8$, II), в том числе с близкими ориентировками максимумов. В определенных условиях трещины цементируются и не оказывают влияние на последующее разрывообразование.

В целом, имеющиеся структурно-вещественные неоднородности различных типов незначительно влияют на структурный рисунок сети тектонических трещин и не препятствуют применению структурно-парагенетического метода.

Таким образом, большое внимание в работе уделено вопросам первоначальной обработки исходных данных. Сравнительный анализ диаграмм 
трещиноватости рекомендуется проводить с учетом специальных критериев сравнения, которые минимизируют ошибки случайного совпадения и обеспечивают надежность полученных решений. Этому способствует также знание особенностей интерпретации диаграмм в связи с различным строением разрывных сетей и вмещающих массивов горных пород.

\section{5. ЗАКЛЮЧЕНИЕ}

Рассмотрены прикладные вопросы проведения нового структурно-парагенетического анализа трещин, связанные с подготовительным этапом по сбору данных в поле и с этапом их начальной обработки на стадии выявления локальных разломов и полей напряжений. В основе статьи - опыт массовых измерений ориентировок трещин и последующего анализа 234 круговых диаграмм, для каждой из которых получено от одного до трех локальных решений о типе и ориентировке разломной зоны и поля напряженийразного типа и различного залегания. Особенности применения анализа трещин на разных участках позволили предложить практические дополнения и рекомендации к методике.

\section{Особенности подготовительного этапа}

Предварительная оценка трещинной сети коренного выхода. Наличие трещин тектонического происхождения в качестве исходных данных как основное условие для применения методики оценивается посредством анализа признаков тектонической трещиноватости: системная или хаотическая (многосистемная) структура сети (не менее трех систем) и сколовый тип трещин, а также протяженность, прямолинейность, пересечение структурно-вещественных границ, закономерная ориентировка в разломной зоне, следы смещений на плоскостях.

Применение метода для анализа трещиноватости других генетических типов допускается при наличии вышеназванных признаков, свидетельствующих о существенном влиянии тектонических напряжений на формирование трещин. Таким образом, можно анализировать трещинные сети в интрузивных, осадочных породах, в том числе слабосцементированных, а также в зоне гипергенеза или техногенного воздействия. Чем больше доля тектонических трещин в смешанных сетях, тем информативнее результаты анализа.

Приемы проведения массовых измерений трещин. Увеличение числа пунктов наблюдения с массовым замером ориентировок трещин повышает досто- верность метода. Рекомендуется производить отдельные замеры на участках, значительно различающихся по степени нарушенности пород трещинами, типу горных пород, геологическому строению. Для замера следует выбирать по возможности изометричную часть коренного выхода с меньшей степенью выветрелости.

Трещины следует измерять подряд, без пропусков, не выбирая «удобные» для замера поверхности; значения элементов залегания не округляются. Размер площадки для одного замера при оптимальном количестве трещин (100 штук)

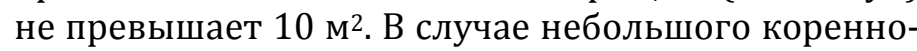
го выхода с малым количеством трещин следует производить измерения только при наличии сколовых разрывов. Кроме того, проводится стандартное геолого-структурное описание коренного выхода.

\section{Особенности этапа обработки}

Построение круговых диаграмм производится на верхней полусфере равноугольной проекции Вульфа для правильного сопоставления с эталонными трафаретами. В ходе анализа используются все максимумы на диаграмме, в том числе и самой низкой интенсивности.

Сравнительный анализ диаграмм. Идентификация сложных сетей трещин путем сравнения с эталонами обеспечивает выбор наиболее достоверных решений при использовании таких критериев оценки, как специфический структурный рисунок эталонной диаграммы (совокупность троек систем трещин), качественные и количественные характеристики трещинной сети (угол у сопряженных сколов, интенсивность систем в тройках, направленные разбросы полюсов трещин в системах, распределение трещин скола и отрыва), геологоструктурная информация о коренном выходе (признаки смещений, тектониты, зоны трещиноватости, рассланцевания), повторяемость парагенезиса в соседних пунктах наблюдения. Несколько локальных решений, полученных для одной трещинной сети, свидетельствуют о разновозрастных напряженных состояниях.

Вопросы интерпретации трещинных сетей. При сравнительном анализе диаграмм необходимо учитывать отклонения величин углов между главной и второстепенной системами трещин в тройке от среднего эталонного значения, как правило, в пределах статистического размаха вариаций, а также меньшие величины углов и отсутствие дополнительной системы в случае трещинной сети, сформированной в близповерхностных условиях; возможность анализировать нетипичные для метода трещинные парагенезисы на диаграмме (пояс, пи- 
рамида) и парагенезисы разломных зон смешанного морфогенетического типа; незначительное влияние на строение сети структурно-вещественных неоднородностей разрывного и неразрывного типа в горном массиве.

Представленные в статье рекомендации будут полезны для эффективного применения структурно-парагенетического подхода к анализу приразломной трещиноватости. Субъективный фактор в использовании метода разными специалистами снижается до минимума при соблюдении единых приемов работы. При таком подходе результаты анализа отличаются лишь в деталях, что позволяет рекомендовать метод для широкого применения в геологической практике.

\section{6. БЛАГОДАРНОСТИ}

Автор искренне благодарен докт. геол.-мин. наук К.Ж. Семинскому за ценные советы и замечания, а также канд. геол.-мин. наук А.В. Черемных, канд. геол.-мин. наук А.А. Боброву, асп. А.К. Семинскому, вед. инж. А.А. Тарасовой за помощь в экспедиционных работах. Работы выполнены при частичной поддержке РФФИ (проект № 16-05-00154).

\section{7. ЛИТЕРАTУРA / REFERENCES}

Burzunova Yu.P., 2009. Near-fault fracture systems: using the new opportunities of the paragenetic analysis (West Pribaikalie). In: Faulting and seismicity in lithosphere: Tectonophysical Concepts and Results. Proceedings of the All-Russia Conference (Irkutsk, August 18-21, 2009). Vol. 1. IEC SB RAS, Irkutsk, p. 20-22 (in Russian) [Бурзунова Ю.П. Приразломные трещинные сети: применение новых возможностей парагенетического анализа (на одном из участков Западного Прибайкалья) // Разломообразование и сейсмичность в литосфере: тектонофизические концепции и следствия: Материалы Всероссийского совещания (г. Иркутск, 18-21 августа 2009 г.). Иркутск: Институт земной коры СО РАН, 2009. Т. 1. С. 20-22].

Burzunova Yu.P., 2011. The angles between conjugate tectonic fracture sets in standard and natural paragenesis forming in different dynamic conditions. Litosfera (Lithosphere) (2), 94-110 (in Russian) [Бурзунова Ю.П. Углы между сопряженными системами приразломных трещин в идеализированных и природных парагенезисах, формирующихся в различных динамических обстановках // Литосфера. 2011. № 2. С. 94-110].

Burzunova Yu.P., 2013. Possibilities of structural-paragenetic analysis of fractures: local and regional stress fields in the Olkhon area, West Pribaikalie. In: Modern tectonophysics. Methods and results. Proceedings of the $3^{\text {rd }}$ Youth Workshop (Moscow, 14-18 October 2013). Vol. 1. IEP, Moscow, p. 58-66 (in Russian) [Бурзунова Ю.П. Возможности структурно-парагенетического анализа трещин: локальные и региональные поля напряжений Приольхонья (Западное Прибайкалье) // Современная тектонофизика. Методы и результаты: Материалы третьей молодежной школы-семинара (г. Москва, 14-18 октября 2013 г.). М.: ИФ3, 2013. Т. 1. С. 58-66].

Burzunova Үu.P., 2014. Joint systems in rocks of active tectonic regions: irregularity degree estimation. Bulletin of Irkutsk State Technical University (4), 45-49 (in Russian) [Бурзунова Ю.П. Трещинные сети в породах тектонически активных регионов: оценка степени хаотичности // Вестник Иркутского государственного технического университета. 2014. № 4. С. 45-49].

Burzunova Yu.P., 2015. Tazheran syenite massif fault zones (West Pribaikalie) by the results of structural paragenetic analysis of meso-fracturing. Proceedings of Siberian Department of the Section of Earth Sciences Russian Academy of Natural Sciences. Geology, Exploration and Development of Mineral Deposits (1), 58-67 (in Russian) [Бурзунова Ю.П. Разломные зоны Тажеранского массива сиенитов (Западное Прибайкалье) по результатам структурно-парагенетического анализа трещиноватости // Известия Сибирского отделения Секции наук о Земле РАЕН. Геология, разведка и разработка месторождений полезных ископаемых. 2015. № 1. С. 58-67].

Chernyshev S.N., 1983. Rock Fractures. Nauka, Moscow. 240 p. (in Russian) [Чернышев C.H. Трещины горных пород. М.: Наука, 1983. 240 с.].

Danilovich V.N., 1961. Method of Belts in Study of Fracturing Related to the Fault Displacements. Irkutsk Polytechnic Institute, Irkutsk, 47 p. (in Russian) [Данилович B.H. Метод поясов в исследовании трещиноватости, связанной с разрывными смещениями. Иркутск: Иркутский политехнический институт, 1961. 47 с.].

Dodin A.L. (Ed.), 1986. State Geological Map of Russia. Sheet N (47) 48. Scale 1:1000000. VSEGEI, Leningrad (in Russian) [Государственная геологическая карта России. Лист N (47) 48. Масштаб 1: 1000000 / Ред. А.Л. Додин. Л.: ВСЕГЕИ, 1986. Available from: http: //www.geolkarta.ru/list_200.php?idlist=N(47)48\&idlist_d=G\&gen=1\&g=1 (last accessed: March 10, 2017).

Gladkov A.S., Seminskii K.Z., 1999. Nontraditional analysis of fracturing belts on mapping of subhorizontal fault structures (exemplified by the vicinities of Irkutsk). Geologiya i Geofizika (Russian Geology and Geophysics) 40 (2), 213-220.

Goncharov M.A., Talitsky V.G., Frolova N.S., 2005. Introduction to Tectonophysics. Knizhnyj Dom “Universitet”, Moscow, 496 p. (in Russian) [Гончаров М.А., Талицкий В.Г., Фролова Н.С. Введение в тектонофизику. М.: Книжный дом «Университет», 2005. 496 с.].

Gzovsky M.V., 1963. The Main Issues of Tectonophysics and Tectonics of Baydzhansaysky Anticlinorium. Parts III and IV. Publishing House of the USSR Academy of Sciences, Moscow, 544 p. (in Russian) [Гзовский М.В. Основные 
вопросы тектонофизики и тектоника Байджансайского антиклинория. Ч. III, IV. М.: Изд-во АН СССР, 1963. 544 c.].

Gzovsky M.V., 1975. Fundamentals of Tectonophysics. Nauka, Moscow, 536 p. (in Russian) [Гзовский М.В. Основы тектонофизики. М.: Наука, 1975. 536 c].

Hancock P.L., 1985. Brittle microtectonics principles and practice. Journal of Structural Geology 7 (3-4), 437-457. https://doi.org/10.1016/0191-8141(85)90048-3.

Lobatskaya R.M., 1987. Structural Zonation of Faults. Nedra, Moscow, 128 p. (in Russian) [Лобацкая Р.М. Структурная зональность разломов. М.: Недра, 1987. 128 с.].

Mikhailov A.E., 1984. Structural Geology and Geological Mapping. Textbook. Nedra, Moscow, 464 p. (in Russian) [Михайлов A.E. Структурная геология и геологическое картирование. Учебное пособие для вузов. М.: Недра, 1984. 464 с.].

Nevsky V.A., 1979. Fracture Tectonics of Ore Fields and Deposits. Nedra, Moscow, 224 p. (in Russian) [Невский В.A. Трещинная тектоника рудных полей и месторождений. М.: Недра, 1979. 224 с.].

Nikolaev P.N., 1992. Tectonodynamic Analysis Technique. Nedra, Moscow, 295 p. (in Russian) [Николаев П.Н. Методика тектонодинамического анализа. М.: Недра, 1992. 295 с.].

Nikolaevsky V.N., 2010. Collection of Works. Geomechanics. Volume 2. Earth's crust. Nonlinear Seismics. Whirlwinds and Hurricanes. Institute for Computer Research, Moscow-Izhevsk, 560 p. (in Russian) [Николаевский В.Н. Coбрание трудов. Геомеханика. Том 2. Земная кора. Нелинейная сейсмика. Вихри и ураганы. Москва-Ижевск: Институт компьютерных исследований, 2010. 560 с.].

Pluijm B.A., 2004. Earth Structure: An Introduction to Structural Geology and Tectonics. W.W. Norton \& Company, New York, $656 \mathrm{p}$.

Ramsey J.M., Chester F.M., 2004. Hybrid fracture and the transition from extension fracture to shear fracture. Nature 428 (6978), 63-66. https://doi.org/10.1038/nature02333.

Rastsvetaev L.M., 1987. Paragenetic method for the structural analysis of faults. In: A.V. Peive, A.V. Luk'yanov (Eds.), Problems of structural geology and physics of tectonic processes. Part 2. GIN AN SSSR, Moscow, p. 173-235 (in Russian] [Расцветаев Л.М. Парагенетический метод структурного анализа дизъюнктивных тектонических нарушений // Проблемы структурной геологии и физики тектонических процессов. Ч. 2 / Ред. А.В. Пейве, А.В. Лукьянов. М.: ГИН АН СССР, 1987. С. 173-235].

Seminskii K.Zh., 1997. Angle relationships between conjugate joint systems near strike-slip, normal, and thrust fault planes. Transactions (Doklady) of the Russian Academy of Sciences: Earth Science Sections 345 (4), 531-533.

Seminskii K.Zh., Gladkov A.S., Lunina O.V., 2001a. Tectonophysics of the Angara fault zone (southern Siberian platform). Geologiya i Geofizika (Russian Geology and Geophysics) 42 (8), 1252-1262.

Seminskii K.Zh., Karabanov E.B., Kuz'min M.I., 2001b. Faulting in Baikal bottom sediments (studies of drilling core BDP-98). Geologiya i Geofizika (Russian Geology and Geophysics) 42 (1-2), 306-316.

Seminskii K.Zh., Kozhevnikov N.O., Cheremnykh A.V., Pospeeva E.V., Bobrov A.A., Olenchenko V.V., Tugarina M.A., Potapov V.V., Burzunova Yu.P., 2012. Interblock zones of the northwestern Baikal rift: results of geological and geophysical studies along the Bayandai Village - Cape Krestovskii profile. Russian Geology and Geophysics 53 (2), 194-208. https://doi.org/10.1016/j.rgg.2011.12.016.

Seminsky K.Zh., 2003. The Internal Structure of Continental Fault Zones. Tectonophysical Aspect. GEO Branch, Publishing House of SB RAS, Novosibirsk, 243 p. (in Russian) [Семинский К.Ж. Внутренняя структура континентальных разломных зон. Тектонофизический аспект. Новосибирск: Изд-во СО РАН, филиал «Гео», 2003. 243 с.].

Seminsky K.Zh., 2014. Specialized mapping of crustal fault zones. Part 1: Basic theoretical concepts and principles. Geodynamics \& Tectonophysics 5 (2), 445-467 (in Russian) [Семинский К.Ж. Спецкартирование разломных зон земной коры. Статья 1: Теоретические основы и принципы // Геодинамика и тектонофизика. 2014. Т. 5. № 2. C. 445-467]. https://doi.org/10.5800/GT-2014-5-2-0136.

Seminsky K.Zh., 2015. Specialized mapping of crustal fault zones. Part 2: Main stages and prospects. Geodynamics \& Tectonophysics 6 (1), 1-43 (in Russian) [Семинский К.Ж. Спецкартирование разломных зон земной коры. Статья 2: Основные этапы и перспективы // Геодинамика и тектонофизика. 2015. т. 6. № 1. С. 1-43]. https://doi.org/10.5800/GT-2015-6-1-0170.

Seminsky K.Zh., Burzunova Yu.P., 2007. Interpretation of chaotic jointing near fault planes: a new approach. Russian Geology and Geophysics 48 (3), 257-266. https://doi.org/10.1016/j.rgg.2007.02.009.

Seminsky K.Zh., Cheremnykh A.V., 2011. Jointing patterns and stress tensors in Cenozoic sediments of the Baikal rift: development of the structural-genetic approach. Russian Geology and Geophysics 52 (3), 353-367. https://doi.org/ 10.1016/j.rgg.2011.02.008.

Seminsky K.Zh., Gladkov A.S., 1991. The new approach to studies of tectonic fracturing in fault zones. Geologiya $i$ Geofizika (Russian Geology and Geophysics) 32 (5), 130-140 (in Russian) [Семинский К.Ж., Гладков А.C. Новый подход к изучению тектонической трещиноватости в разрывных зонах // Геология и геофизика. 1991. Т. 32. № 5. С. 130-140].

Sherman S.I., 2002. Methodology for Studying and Analyzing Quantitative Parameters of Lithospheric Faults. ISTU Publishing House, Irkutsk, 60 p. (in Russian) [Шерман С.И. Методика изучения и анализа количественных параметров разломов литосферы. Изд-во ИрГТУ, Иркутск, 2002. 60 с.]. 
Sherman S.I., Bornyakov S.A., Buddo V.Yu., 1983. Areas of Dynamic Influence of Faults (Modelling Results). Nauka, Novosibirsk, 110 p. (in Russian) [Шерман С.И., Борняков С.А., Буддо В.Ю. Области динамического влияния разломов (результаты моделирования). Новосибирск: Наука. СО АН СССР, 1983. 110 с.].

Sherman S.I., Seminsky K.Zh., Bornyakov S.A., Adamovich A.N., Lobatskaya R.M., Lysak S.V., Levi K.G., 1992. Faulting in the Lithosphere. Extension Zones. Nauka, Siberian Branch, Novosibirsk, 228 p. (in Russian) [Шерман С.И., Семинский К.Ж., Борняков С.А., Адамович А.Н., Лобацкая Р.М., Лысак С.В., Леви К.Г. Разломообразование в литосфере. Зоны растяжения. Новосибирск: Наука. СО, 1992. 228 с.].

Sibson R.N., 1998. Brittle failure mode plots for compressional and extensional tectonic regimes. Journal of Structure Geology 20 (5), 655-660. https://doi.org/10.1016/S0191-8141(98)00116-3.

Tevelev A.L., 2011. Structural Geology and Geological Mapping. Lectures. Teaching Manual. GERS Publishing House, Tver, 292 p. (in Russian) [Тевелев А.В. Структурная геология и геологическое картирование. Курс лекций. Учебно-методическое пособие. Тверь: Издательство ГЕРС, 2011. 292 с.].

Twiss R.J., 1992. Structural Geology. W.H. Freeman \& Company, New York, 532 p.

Yanshin A.L. (Ed.), 1989. Map of Geological Formations of the Mongolian People's Republic. Scale 1:1500000. The USSR Academy of Sciences. Academy of Sciences of the Mongolian People's Republic. Joint Soviet-Mongolian Scientific Research Geological Expedition of the USSR Academy of Sciences and the Academy of Sciences of the Mongolian People's Republic. Main Department of Geodesy and Cartography (The USSR Council of Ministers), Moscow (in Russian) [Карта геологических формаций Монгольской Народной Республики. Масштаб: 1:1500000 / Ред. А.Л. Яншин. Академия наук СССР. Академия наук МНР. Совместная советско-монгольская научно-исследовательская геологическая экспедиция АН СССР и АН МНР. М.: Главное управление геодезии и картографии при Совете Министров СССР, 1989. Available from: http://neotec.ginras.ru/neomaps/M015_Mongolia_ 1989_Tectonics_Karta-geologicheskih-formaciy-mongolskoy-narodnoy-respubliki.html (last accessed: March 10, 2017).

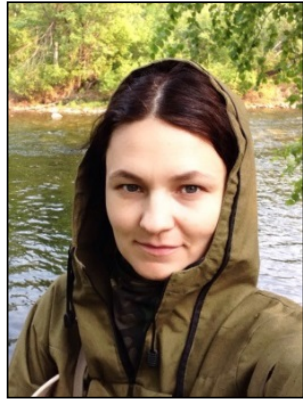

Бурзунова Юлия Петровна, канд. геол.-мин. наук

Институт земной коры СО РАН

664033, Иркутск, ул. Лермонтова, 128, Россия

$\triangle$ e-mail: burzunova@crust.irk.ru

Burzunova, Yulia P., Candidate of Geology and Mineralogy

Institute of the Earth's Crust, Siberian Branch of RAS

128 Lermontov street, Irkutsk 664033, Russia

\e-mail: burzunova@crust.irk.ru 